\title{
The radiative forcing potential of different climate geoengineering options
}

\author{
T. M. Lenton and N. E. Vaughan
}

School of Environmental Sciences, University of East Anglia, Norwich NR4 7TJ, UK

Tyndall Centre for Climate Change Research, UK

Received: 10 December 2008 - Published in Atmos. Chem. Phys. Discuss.: 28 January 2009

Revised: 10 July 2009 - Accepted: 24 July 2009 - Published: 6 August 2009

\begin{abstract}
Climate geoengineering proposals seek to rectify the Earth's current and potential future radiative imbalance, either by reducing the absorption of incoming solar (shortwave) radiation, or by removing $\mathrm{CO}_{2}$ from the atmosphere and transferring it to long-lived reservoirs, thus increasing outgoing longwave radiation. A fundamental criterion for evaluating geoengineering options is their climate cooling effectiveness, which we quantify here in terms of radiative forcing potential. We use a simple analytical approach, based on energy balance considerations and pulse response functions for the decay of $\mathrm{CO}_{2}$ perturbations. This aids transparency compared to calculations with complex numerical models, but is not intended to be definitive. It allows us to compare the relative effectiveness of a range of proposals. We consider geoengineering options as additional to large reductions in $\mathrm{CO}_{2}$ emissions. By 2050, some land carbon cycle geoengineering options could be of comparable magnitude to mitigation "wedges", but only stratospheric aerosol injections, albedo enhancement of marine stratocumulus clouds, or sunshades in space have the potential to cool the climate back toward its pre-industrial state. Strong mitigation, combined with global-scale air capture and storage, afforestation, and bio-char production, i.e. enhanced $\mathrm{CO}_{2}$ sinks, might be able to bring $\mathrm{CO}_{2}$ back to its pre-industrial level by 2100 , thus removing the need for other geoengineering. Alternatively, strong mitigation stabilising $\mathrm{CO}_{2}$ at $500 \mathrm{ppm}$, combined with geoengineered increases in the albedo of marine stratiform clouds, grasslands, croplands and human settlements might achieve a patchy cancellation of radiative forcing. Ocean fertilisation options are only worthwhile if sus-
\end{abstract}

Correspondence to: T. M. Lenton

(t.lenton@uea.ac.uk) tained on a millennial timescale and phosphorus addition may have greater long-term potential than iron or nitrogen fertilisation. Enhancing ocean upwelling or downwelling have trivial effects on any meaningful timescale. Our approach provides a common framework for the evaluation of climate geoengineering proposals, and our results should help inform the prioritisation of further research into them.

\section{Introduction}

Geoengineering has been defined as "...large-scale engineering of our environment in order to combat or counteract the effects of changes in atmospheric chemistry" (NAS, 1992), in particular to mediate the effects of elevated greenhouse gas, especially carbon dioxide $\left(\mathrm{CO}_{2}\right)$, concentrations. In contrast, mitigation refers to activities that reduce anthropogenic emissions of greenhouse gases (particularly $\mathrm{CO}_{2}$ ). The realisation that existing mitigation efforts are proving wholly ineffectual at the global scale, as evidenced by post2000 trends in anthropogenic $\mathrm{CO}_{2}$ emissions (Canadell et al., 2007), has fuelled a recent resurgence of interest in geoengineering (Crutzen, 2006), with a growing number of proposals being aired in the scientific literature (Boyd, 2008). The proposed roles for geoengineering vary from perpetually counteracting the radiative forcing due to mitigated anthropogenic greenhouse gas emissions (Wigley, 2006), to only being deployed if dangerous climate change is imminent or underway (Angel, 2006). Either way, accurate quantifications of potential climate cooling effects is crucial. Yet there is something of a shortage of these, especially for carbon cycle geoengineering proposals where most efforts stop at quantifying an effect on atmospheric $\mathrm{CO}_{2}$ (if indeed they get that far). As

Published by Copernicus Publications on behalf of the European Geosciences Union. 
part of a broader review of climate geoengineering proposals (Vaughan and Lenton, 2009), we have sought to quantify, in a common currency, the climate cooling potential of a wide range of geoengineering proposals discussed in the recent literature. "Will it be effective?" is certainly not the only criterion against which geoengineering proposals should be judged (Boyd, 2008), but only measures that pass the basic test of potential effectiveness need be considered further.

At the simplest level, the surface temperature of the Earth results from the net balance of incoming solar (shortwave) radiation and outgoing terrestrial (longwave) radiation (Kiehl and Trenberth, 1997). Geoengineering options (Fig. 1) attempt to rectify the current and potential future radiative imbalance via either: (1) reducing the amount of solar (shortwave) radiation absorbed by the Earth, or (2) increasing the amount of longwave radiation emitted by the Earth. The shortwave options (1) can be subdivided into (a) those that seek to reduce the amount of solar radiation reaching the top of the atmosphere, and (b) those that seek to increase the reflection of shortwave radiation (albedo) within the atmosphere or at the surface. The longwave options (2) primarily involve removing $\mathrm{CO}_{2}$ from the atmosphere and preventing (at least some of) it from returning there. They can be subdivided into the enhancement or creation of (a) land and (b) ocean carbon sinks. Other climate geoengineering approaches are conceivable, for example, increasing shortwave absorption in the stratosphere by injecting soot particles (Crutzen, 2006), or increasing outgoing longwave radiation by dispersing clouds over the polar ice caps, but we confine our attention to proposals focused on in the recent literature.

Shortwave geoengineering proposals (Fig. 1) start with reflecting away (or shading out, as seen from Earth) a fraction of incoming solar radiation by placing objects in a solar orbit, e.g. at the inner Lagrange point (L1) (Angel, 2006). Alternatively, sunshades could be placed in an Earth orbit (NAS, 1992; Pearson et al., 2006). Once solar radiation enters the atmosphere, its reflection back to space could be enhanced by adding sulphate aerosol (Crutzen, 2006), soot or manufactured particles (Teller et al., 1997, 2002) to the stratosphere. Adding sulphate aerosols to the troposphere (NAS, 1992) has been ruled out due to negative impacts on human health, the greater loading required than the equivalent intervention in the stratosphere, and the need for multiple injection locations (Crutzen, 2006; MacCracken, 2006). However, increasing the reflectivity of low level marine stratiform clouds by mechanical (Latham, 1990) or biological (Wingenter et al., 2007) generation of cloud condensation nuclei $(\mathrm{CCN})$ is being considered. Finally, the reflectivity of the Earth's surface could be increased, with recent proposals focused on the land surface, including albedo modification of deserts (Gaskill, 2004), grasslands (Hamwey, 2007), croplands (Ridgwell et al., 2009), human settlements (Hamwey, 2007), and urban areas (Akbari et al., 2009).
Options for enhancing the land carbon sink (Fig. 1), involve increasing the net uptake of $\mathrm{CO}_{2}$ (either by plants or by chemical means) and successfully storing the captured carbon either in vegetation biomass, as charcoal or organic carbon in soils, or in geological storage sites. Afforestation and reforestation sequesters carbon in the biomass of trees (NAS, 1992), and is also currently treated as a mitigation option by the Intergovernmental Panel on Climate Change (IPCC). The production of bio-char by pyrolysis (combustion largely in the absence of oxygen), converts up to $50 \%$ of the carbon in biomass to a long-lived form - charcoal, which can then be added to soils (the rest produces $\mathrm{CO}_{2}$ which can also be captured and stored) (Lehmann et al., 2006). "Air capture and storage" is used here to cover two recently widely discussed pathways of capturing $\mathrm{CO}_{2}$ from the free air and conveying it to geological storage sites. Bio-energy with carbon storage (BECS) refers to a variety of biomass and bio-fuel production pathways, based around forestry, sugar cane and switchgrass production, with capture of the $\mathrm{CO}_{2}$ produced in the processes of fermenting fuels and combustion, followed by carbon storage (Read and Lermit, 2005). Chemical capture and storage is achieved by using ambient (wind) or activelygenerated flow over a sorbent material (such as sodium hydroxide, $\mathrm{NaOH}$ ) resulting in a pure stream of $\mathrm{CO}_{2}$ gas which is then compressed and transported to a storage site (Lackner et al., 1995; Keith et al., 2006; Zeman, 2007).

Options for enhancing the ocean carbon sink (Fig. 1) generally depend on successfully transporting more carbon to the deep ocean, via either the biological (soft tissue) pump or the solubility pump, and increasing carbon storage there. We also consider the potential for increasing carbon storage in coastal and shelf sea sediments via increased phosphorus runoff from the land. Suggestions for enhancing the biological (soft tissue) pump involve adding limiting nutrients derived from the land surface to appropriate surface areas of the ocean (Lampitt et al., 2008), including phosphorus, nitrogen and iron, or enhancing the upwelling of nutrient-rich waters (Lovelock and Rapley, 2007), potentially stimulating nitrogen fixation (Karl and Letelier, 2008). Suggestions for enhancing the solubility pump include increasing deep water production (i.e. downwelling in key regions) (Zhou and Flynn, 2005). Alternatively, increasing the alkalinity of the oceans through the addition of carbonate minerals should allow more $\mathrm{CO}_{2}$ to be absorbed (Kheshgi, 1995; Harvey, 2008).

To compare these geoengineering options, we quantify the potential of each to cool the climate, in terms of radiative forcing (RF), and compare our simple estimates to published values, where they exist. Radiative forcing describes any imbalance in Earth's radiation budget caused by human or natural interventions in the climate system. Once radiative forcing is applied, the climate system tends to adjust to recover energy balance, which usually takes the form of changes in temperature at various levels. The IPCC convention is to measure radiative forcing in terms of the change in net 


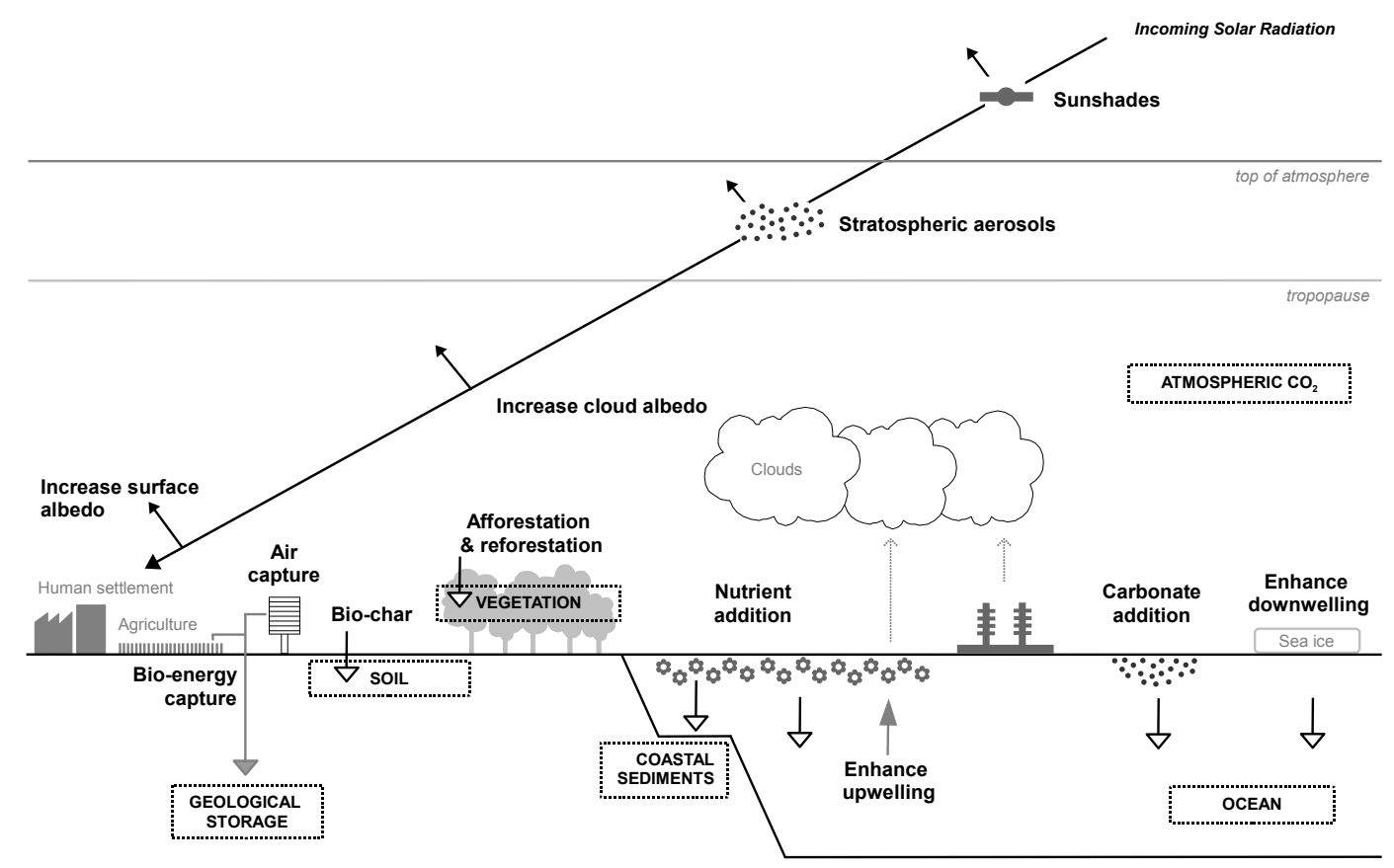

Fig. 1. Schematic overview of the climate geoengineering proposals considered. Black arrowheads indicate shortwave radiation, white arrowheads indicate enhancement of natural flows of carbon, grey downward arrow indicates engineered flow of carbon, grey upward arrow indicates engineered flow of water, dotted vertical arrows illustrate sources of cloud condensation nuclei, and dashed boxes indicate carbon stores. From Vaughan and Lenton (2009), not to scale.

irradiance at the tropopause, after allowing stratospheric temperatures to readjust to radiative equilibrium (IPCC, 2001, 2007). The tropopause is chosen because there is a direct relationship between radiative forcing across it and surface temperature change; $\Delta T_{s}=\lambda \mathrm{RF}$, where $\lambda$ is a climate sensitivity parameter. This relationship holds reasonably well (within a given model) for most forcing factors, especially changes in well mixed greenhouse gases (IPCC, 2007). However, the true value of $\lambda$ is not precisely known, ranging over 0.6 to $1.2^{\circ} \mathrm{CW}^{-1} \mathrm{~m}^{2}$ in current models, with a value of $\lambda=0.86^{\circ} \mathrm{CW}^{-1} \mathrm{~m}^{2}$ corresponding to their mean equilibrium response to doubling $\mathrm{CO}_{2}$ of $\Delta T_{s}=3.2^{\circ} \mathrm{C}$ (IPCC, 2007). Allowing stratospheric temperatures to adjust is important for correctly evaluating the effect of changes in stratospheric ozone concentration and has a 5-10\% effect on the forcing due to some other greenhouse gases, but it is less important for shortwave forcing agents. For most shortwave forcing agents, the instantaneous radiative forcing at the top of the atmosphere (TOA) is linked to surface temperature change and can be substituted for the stratospheric-adjusted radiative forcing at the tropopause (IPCC, 2007).

We calculate the effect of most shortwave geoengineering options on the instantaneous TOA radiative forcing, because this allows us to make use of the shortwave part of the Earth's annual global mean energy budget (Kiehl and Trenberth, 1997). We compare the resulting values to the effect of different $\mathrm{CO}_{2}$ geoengineering options on the stratospheric- adjusted radiative forcing at the tropopause, calculated from a well-known, simple formula (IPCC, 2001, 2007). Recent studies suggest that the "efficacy" of different shortwave and longwave radiative forcing agents - their ability to effect surface temperature changes - differs somewhat (Hansen et al., 2005). Hence we adjust for efficacy where it differs significantly from that of $\mathrm{CO}_{2}$ (see Results).

In the geoengineering literature, either the present anthropogenic radiative forcing $\left(+1.6[-1.0 /+0.8] \mathrm{W} \mathrm{m}^{-2}\right.$ in 2005) or that due to a doubling of atmospheric $\mathrm{CO}_{2}\left(+3.71 \mathrm{~W} \mathrm{~m}^{-2}\right)$ (IPCC, 2007), are typically taken as the targets to counteract. However, actual anthropogenic radiative forcing has varied, and will continue to vary, over time. By radiative forcing "potential" we generally mean the most negative radiative forcing that could physically be achieved by a particular option (irrespective of whether it is sensible or desirable, for other reasons, to achieve it). The exceptions are space-based measures which have considerable capacity to be scaled up and atmospheric aerosol and CCN measures which have limited capacity to be scaled up. Geoengineered radiative forcing effects themselves will all decay over time, although at widely differing rates. Shortwave geoengineering options generally have rather short lifetimes (from a few decades for spacecraft at the L1 point, a few years for stratospheric sulphate, to a few days for tropospheric CCN). This is usually addressed by arguing that short-lived measures would be continually replenished, and we calculate their radiative 
forcing potential on this basis, making them appear timeindependent. In truth, all the options would take some time to develop and deploy and may never reach their estimated potential.

The longwave geoengineering options have to be considered in a time dependent manner, because they involve interfering with a dynamic carbon cycle. Hence we consider timedependent scenarios of $\mathrm{CO}_{2}$ removal from the atmosphere. There is an added complication that effects on atmospheric $\mathrm{CO}_{2}$ will decay over time, due to the counter-balancing response of ocean and land carbon reservoirs to atmospheric perturbations. Effects will also decay if carbon storage is not permanent and $\mathrm{CO}_{2}$ is leaked back to the atmosphere. Thus, to calculate an effect on atmospheric $\mathrm{CO}_{2}$ one must specify a timescale of interest. To calculate a corresponding impact on radiative forcing one also needs to account for the fact that the sensitivity of radiative forcing to a given change in $\mathrm{CO}_{2}$ depends inversely on the absolute concentration of $\mathrm{CO}_{2}$ (see Methods). This demands that we specify a reference scenario for $\mathrm{CO}_{2}$ concentration. We choose to focus on two intermediate time horizons of interest to policy makers, 2050 and 2100 , and also consider long-term effects on the millennial timescale. Ultimately, the only way to return atmospheric $\mathrm{CO}_{2}$ to pre-industrial levels is to permanently store (in some combination of the crust, sediments, soils, ocean, and terrestrial biosphere) an equivalent amount of $\mathrm{CO}_{2}$ to the total emitted to the atmosphere.

We deliberately take a simple analytical approach to quantify radiative forcing potentials, based on energy balance considerations and pulse response functions for the decay of $\mathrm{CO}_{2}$ perturbations. The aim is to provide transparent results that are accurate to first order. In revising this paper we have linked our simple formulae for quantifying the effect of shortwave geoengineering options to the results of complex numerical models, including radiative transfer codes. Our global mean approach is at a similar (or somewhat higher) level of complexity to several analytical calculations in the geoengineering literature, e.g. (Latham et al., 2008; Akbari et al., 2009). It allows us to compare the relative effectiveness of a range of proposals, but is not intended to be definitive. Clearly our estimates can be improved upon and we encourage interested readers to do so.

\section{Methods}

\subsection{Shortwave options}

We quantify shortwave geoengineering options based on simple considerations of their effect on the Earth's annual global mean energy balance, making some adjustments for land or ocean focused proposals. For a wide range of forcing agents, some spatially uniform, some quite heterogeneous, the same global magnitude of radiative forcing results in a similar pattern of surface air temperature changes (Hansen et al., 2005). The annual global mean flux of solar radiation at the top of the atmosphere (TOA) is $S_{0}=342 \mathrm{~W} \mathrm{~m}^{-2}$. A total of $107 \mathrm{~W} \mathrm{~m}^{-2}$ is reflected back to space, corresponding to an average planetary albedo $\alpha_{p}=107 / 342=0.313$, and a total of $235 \mathrm{~W} \mathrm{~m}^{-2}$ is absorbed (Kiehl and Trenberth, 1997). Shortwave geoengineering proposals aim to decrease the $235 \mathrm{~W} \mathrm{~m}^{-2}$ absorbed, either by shading the Earth, or by increasing the planetary albedo.

For measures that seek to reduce the amount of solar radiation reaching the Earth, by $\Delta S\left(\mathrm{~W} \mathrm{~m}^{-2}\right)$, the resulting instantaneous TOA radiative forcing, $\mathrm{RF}$ is given by:

$\mathrm{RF}=\Delta S\left(1-\alpha_{p}\right)$

In other words, the reduction in incoming solar radiation must exceed the required radiative forcing by a factor of $1 /\left(1-\alpha_{p}\right)=1.456$. Existing simulations suggest that if a given global reduction in incoming solar radiation is concentrated in a particular region, this does not significantly affect the resulting global surface temperature change (Caldeira and Wood, 2008). Concentrating a reduction in solar insolation in the high latitudes has a smaller effect on the total radiation budget (because of the typically high solar zenith angle), but positive climate feedbacks are regionally stronger there, so the effect on global surface temperature is about the same as for an equivalent global reduction in solar insolation (Caldeira and Wood, 2008).

For the effect of stratospheric sulphate aerosol injections we adopt a simple relationship between aerosol optical depth, $\tau$ (measured at $0.55 \mu \mathrm{m}$ wavelength), and adjusted radiative forcing (at the tropopause after stratospheric temperatures are allowed to adjust) based on simulations of the aftermath of the Mt Pinatubo eruption (Hansen et al., 2005):

$\mathrm{RF}=-24 \tau$

For sulphate aerosol that is deliberately engineered to have an optimal effective radius, a somewhat lower optical depth would be required to achieve a given radiative forcing. However, aggregation would degrade the radiative forcing effect of the aerosol over time. Different aerosol materials (e.g. soot) have quite different radiative properties and equivalent simple relationships have yet to be derived (existing results are summarised in Sect. 3.1.2).

For measures that seek to increase the planetary albedo by an amount $\Delta \alpha_{p}$, the corresponding instantaneous TOA radiative forcing is given by:

$\mathrm{RF}=-S_{0} \Delta \alpha_{p}$

However, changes in atmosphere, cloud or surface albedo, even if globally and uniformly applied, do not produce equivalent changes in planetary albedo, because of absorption and reflection occurring elsewhere. In particular, the altitude of a change in albedo (as well as its spectral character) will determine how much prior absorption and reflection has occurred, and how much subsequent absorption and reflection 
occurs, which in turn will alter the impact on the planetary albedo (i.e. the change in outgoing solar radiation flux at the top of the atmosphere). For proposals that are focused either on land or over the ocean an adjustment can be made to the solar radiation at the top of the atmosphere $\left(S_{0}\right)$, which is $\sim 330 \mathrm{~W} \mathrm{~m}^{-2}$ on average over the land and $\sim 345 \mathrm{~W} \mathrm{~m}^{-2}$ over the ocean (Trenberth et al., 2009).

In general, changes in atmosphere, cloud or surface albedo $(\Delta \alpha)$ can be approximately linearly related to changes in planetary albedo:

$\Delta \alpha_{p}=f_{a} f_{\text {Earth }} \Delta \alpha$

Where $f_{\text {Earth }}$ is the fraction of the Earth's surface area over which a change in albedo is applied, and $f_{a}<1$ encapsulates the effects of absorption and reflection in other layers. The product $f_{\text {Earth }} \cdot \Delta \alpha$ represents the global average albedo change of a layer (either surface, $\Delta \alpha_{s}$, or atmosphere, $\Delta \alpha_{a}$ ). Data for areal coverage of different surface types and hence $f_{\text {Earth }}$ are obtained from the International Geosphere-Biosphere Programme - Data and Information System (IGBP-DIS) (Loveland et al., 2000) and/or University of Maryland (UMd) (Hansen et al., 2000) land cover datasets.

For surface albedo changes, the linear relationship with planetary albedo changes, Eq. (4), is supported by the results of radiative transfer models (Chen and Ohring, 1984; Li and Garand, 1994). Under a clear-sky, $f_{a}$ represents the mean effective "two-way" transmittance of the atmosphere:

$f_{a}=T_{a}^{2}$

where $T_{a}$ is an atmospheric transmittance factor. From the clear-sky results of a radiative transfer model (Lacis and Hansen, 1974), $f_{a}=0.730\left(T_{a}=0.854\right)$ in the annual global mean, similarly for a fixed solar zenith angle of $60^{\circ} f_{a}=0.729$, and two different sets of observational data give $f_{a}=0.756$ and $f_{a}=0.676$ (Chen and Ohring, 1984). A different radiative transfer model that additionally includes aerosols and variation in the albedo of some surfaces with solar zenith angle gives comparable clear-sky results ( $\mathrm{Li}$ and Garand, 1994) (e.g. for a solar zenith angle of $60^{\circ}$ and a dry column, the maximum value of $f_{a}=0.759$ ).

However, cloudy skies significantly reduce transmittance to and from the surface and hence the global annual mean value of $f_{a}$. To estimate their effect we consider the average flux of downward shortwave radiation at the land surface, which has recently been estimated at $184.7 \mathrm{~W} \mathrm{~m}^{-2}$ (Trenberth et al., 2009). Multiplying this flux by $\Delta \alpha_{s}$ gives an estimate of surface radiative forcing (due to a given change in surface albedo). Some existing estimates (Hamwey, 2007) liken this to radiative forcing at TOA, but that ignores absorption (or further reflection) of the radiation reflected from the surface on its way to the top of the atmosphere. Here we assume that $T_{a}=0.854$ of the radiation reflected from the surface reaches the top of the atmosphere (it all leaves through a clear sky) giving $f_{a}=0.854 \times 184.7 / 330=0.478$ on average over land. Our broadband approach does not account for spectral variations in absorption or albedo, in particular, vegetation is most reflective at a range of solar near-infrared wavelengths where water vapour absorption is strongest, but clouds are most reflective at shorter, visible wavelengths. To accurately assess such spectral effects would require a full radiative transfer model. We use the mean incident radiation over land and assume $f_{a} \sim 0.48$ for land surface reflection unless otherwise stated.

For proposals to alter the Earth's albedo that are seasonally and/or latitudinally biased, our approach could be improved by including a more appropriate flux of solar radiation at the TOA than the mean over land, and by considering the effects of systematic deviations in the solar zenith angle from the global mean $60^{\circ}$. As solar zenith angle increases, $f_{a}$ decreases due to the greater absorption along longer path lengths of sunlight through the atmosphere ( $\mathrm{Li}$ and Garand, 1994). Also, surfaces generally have higher albedo at higher solar zenith angle, with some surfaces (e.g. grassland, arable land) experiencing a greater change in albedo for a given change in solar zenith angle than others (e.g. forest) (Briegleb et al., 1986). Some formulae for estimating these effects are given elsewhere (Lenton and Vaughan, 2009). In general, for surface albedo alterations biased to the low latitudes and/or summer season, the incident radiation $\left(S_{0}\right)$ will tend to be higher but the change in surface albedo will tend to be smaller than suggested by the global average approach (especially for e.g. grassland), and positive feedback determining surface temperature change will tend to be weaker. Conversely for surface albedo alterations biased to the high latitudes and/or winter season, the incident radiation will tend to be lower but the change in surface albedo will tend to be higher than suggested by the global average approach (especially for e.g. grassland), and positive climate feedback will tend to be stronger.

Proposals to increase the albedo of marine stratiform clouds hinge on adding aerosols to the clouds and hence increasing the number density of cloud droplets, which is often called the "first indirect aerosol effect" or "Twomey effect" (Twomey, 1974). Aerosol number concentration, $N_{a}$, can be related to cloud droplet number density, $N_{d}$, by:

$N_{d}=N_{a}^{\gamma}$

The value of the power $\gamma$, which depends on the hygroscopicity of the aerosol, is a critical uncertainty. IPCC (2007) give $\gamma=0.06-0.48$ from measurements over land (Feingold et al., 2003). However, $\gamma=0.7$ has been suggested as typical (Feingold et al., 2003).

Cloud droplet number density can be related to effective radius, $r_{e}$, by:

$r_{e}=k\left(N_{d}\right)^{-1 / 3}$

where $k$ is a constant that can be derived from observations, e.g. (Twohy et al., 2005). 
Effective radius can be related to cloud optical depth, $\tau$, by:

$\tau=\frac{3 l h}{2 \rho_{w} r_{e}}$

where $l$ is cloud liquid water content, $h$ is cloud height, and $\rho_{w}$ is density of water. The Twomey effect assumes no change in cloud liquid water path $(l \cdot h)$ with changes in $N_{d}$. Therefore:

$\tau=K\left(N_{a}\right)^{\gamma / 3}$

where $K$ is an amalgamated constant.

Finally, cloud optical depth can be related to cloud albedo, $\alpha_{c}$, using e.g. the Eddington approximation:

$\alpha_{c}=\frac{0.75(1-g) \tau}{1+0.75(1-g) \tau}$

where $g$ is an asymmetry factor and $g=0.85$ is used elsewhere (Twohy et al., 2005). Other relations between optical depth and cloud albedo based on the two-stream approximation could be adopted, e.g. (Roberts et al., 2008). From differentiating (10), the change in cloud albedo:

$\Delta \alpha \approx \frac{0.75(1-g)}{(1+0.75(1-g) \tau)^{2}} \Delta \tau$

Thus, the sensitivity of cloud albedo to changes in optical depth decreases with increasing optical depth. We take $\tau=10$ and $\alpha_{c}=0.53$ as a representative case and choose $\gamma=0.7$ to obtain minimum estimates of required changes in $N_{a}$ to produce a given $\Delta \alpha$.

To convert cloud albedo changes, $\Delta \alpha$, into planetary albedo changes, assuming an otherwise clear sky above and ignoring changes in back reflection from the surface below the cloud, one can use Eq. (5) (Roberts et al., 2008). In this case, $T_{a}$ represents the atmospheric transmittance to (and from) the altitude of the top of the cloud. For cloud tops at $1.6 \mathrm{~km}$ above sea level $T_{a}=0.925\left(f_{a}=0.856\right)$ (Roberts et al., 2008). The altitude of marine stratocumulus cloud tops is often lower than this and the transmittance correspondingly lower. Equation (5) gives a slight overestimate because it does not account for the reduction in back-reflection from the surface below the cloud that would occur due to increases in $\alpha_{c}$. However, these changes in back reflection will be modest because the ocean surface albedo is low, $\alpha_{s}=0.09$ on average (Trenberth et al., 2009), and transmittance through (and below) the cloud, $T_{c}$, is low, typically $T_{c} \sim 0.5$. Assuming surface-reflected radiation goes back through the cloud then a factor of $\left(1-T_{c}^{2} \alpha_{s}\right)=0.9775$ is introduced as a multiplier in Eq. (5) and $f_{a} \sim 0.84$.

There is scope for a second indirect aerosol effect, whereby smaller cloud droplets form raindrops less effectively, lengthening the lifetime of clouds and thus potentially increasing their liquid water path and/or their fractional coverage (Albrecht, 1989). Such effects would increase the magnitude of negative radiative forcing, following Eqs. (4) or (8) above. However, this effect would operate in the opposite direction if entrainment of dry air from above the clouds is increased (Ackerman et al., 2004). Given the uncertainty over its sign we do not include an estimate of the second indirect aerosol effect.

Where significant, the results are adjusted for the "efficacy" of different shortwave forcing agents, where efficacy refers to the change in surface temperature caused by a given change in radiative forcing, relative to that due to changing atmospheric $\mathrm{CO}_{2}$ (Hansen et al., 2005) (and we consider efficacy relative to a doubling of preindustrial $\mathrm{CO}_{2}$ ). Generally, the efficacy of globally uniform shortwave forcing (by e.g. reducing the solar constant) is somewhat less than that due to $\mathrm{CO}_{2}$ because it is biased to the lower latitudes where positive climate feedbacks are weaker, whereas longwave forcing is more uniform, and in the higher latitudes there are stronger positive climate feedbacks.

\subsection{Longwave $\left(\mathrm{CO}_{2}\right)$ options}

We quantify longwave geoengineering options based on their effect on atmospheric $\mathrm{CO}_{2}$ concentration and hence the stratospheric-adjusted radiative forcing at the tropopause (IPCC, 2001, 2007). The radiative forcing due to specific carbon cycle geoengineering activities depends both on their effect on atmospheric $\mathrm{CO}_{2}$ at a given time and on the absolute value of atmospheric $\mathrm{CO}_{2}$ at that time. Radiative forcing is, to a reasonable approximation, a logarithmic function of $\mathrm{CO}_{2}$ :

$\mathrm{RF}=\beta \ln \frac{\mathrm{CO}_{2}}{\mathrm{CO}_{2, \text { ref }}}$

Here $\mathrm{CO}_{2}$ (in ppm) is the concentration in the atmosphere after a given time, $\mathrm{CO}_{2}$,ref is a reference concentration, and $\beta=5.35 \mathrm{~W} \mathrm{~m}^{-2}$ from (IPCC, 2001). Typically the preindustrial $\mathrm{CO}_{2,1800}=278 \mathrm{ppm}=\mathrm{CO}_{2 \text {, ref }}$ is specified. Then, for example, the 2005 value of $\mathrm{CO}_{2}=379 \mathrm{ppm}$ resulted in an $\mathrm{RF}$ of $1.66 \mathrm{~W} \mathrm{~m}^{-2}$ (IPCC, 2007). The logarithmic relationship means that the sensitivity of $\mathrm{RF}$ to $\mathrm{CO}_{2}\left(\mathrm{~W} \mathrm{~m}^{-2} \mathrm{ppm}^{-1}\right)$ is inversely related to the concentration of $\mathrm{CO}_{2}$ :

$\frac{d \mathrm{RF}}{d \mathrm{CO}_{2}}=\frac{\beta}{\mathrm{CO}_{2}}$

Thus the present sensitivity (using a 2005 concentration of $\mathrm{CO}_{2}=379 \mathrm{ppm}$ ) is $0.0141 \mathrm{~W} \mathrm{~m}^{-2} \mathrm{ppm}^{-1}$, whereas the pre-industrial sensitivity was $0.0192 \mathrm{~W} \mathrm{~m}^{-2} \mathrm{ppm}^{-1}$ and at double pre-industrial $\mathrm{CO}_{2}$ the sensitivity will be $0.0096 \mathrm{~W} \mathrm{~m}^{-2} \mathrm{ppm}^{-1}$. In general, the radiative forcing effect of a particular carbon cycle geoengineering activity at a given time, $t$, can be calculated from:

$\mathrm{RF}(t) \approx \frac{\Delta C_{\mathrm{atm}}}{k} \frac{\beta}{\mathrm{CO}_{2}(t)}$

where $\Delta C_{\text {atm }}$ (in $\mathrm{PgC}$ ) is the amount of $\mathrm{CO}_{2}$ that has been removed from the atmosphere at that time (hence a negative 
number), $k=2.14 \mathrm{PgC} \mathrm{ppm}^{-1}$ is a simple conversion factor, and $\mathrm{CO}_{2}(t)$ (in ppm) is the reference state that atmospheric $\mathrm{CO}_{2}$ would be in, in the absence of geoengineering, at that time. This immediately suggests a potential synergy between mitigation action (reducing $\mathrm{CO}_{2}$ ) and the effectiveness of carbon cycle geoengineering (increasing the magnitude of $\Delta C_{\text {atm }}$ ) because a given reduction in atmospheric $\mathrm{CO}_{2}$ has a greater radiative forcing effect at lower $\mathrm{CO}_{2}$. However, as we will show below, a given geoengineering scenario ultimately has a greater effect on $\mathrm{CO}_{2}$ at higher concentrations of $\mathrm{CO}_{2}$ (i.e. in scenarios with larger total emissions). To make estimates of $\mathrm{RF}(t)$ we calculate $\Delta C_{\text {atm }}$ and specify a reference $\mathrm{CO}_{2}(t)$.

First we consider the calculation of effects on atmospheric $\mathrm{CO}_{2}\left(\Delta C_{\mathrm{atm}}\right)$ over time. Adding $\mathrm{CO}_{2}$ to the atmosphere or removing $\mathrm{CO}_{2}$ from the atmosphere triggers responses from the ocean and land reservoirs that are continuously exchanging $\mathrm{CO}_{2}$ with the atmosphere. The result is that any perturbation to atmospheric $\mathrm{CO}_{2}$, whether an increase or a decrease, decays over time towards around $20 \%$ of its original size on a millennial timescale. The fraction of the original perturbation remaining after a given time, $\Delta t$ (in years), is called the airborne fraction, $f(\Delta t)$. It is a complex function containing multiple decay timescales, related to multiple land and ocean carbon reservoirs. For relatively small perturbations, it can be approximated, from the Bern carbon cycle model (Joos et al., 1996) by:

$$
\begin{aligned}
f(\Delta t) & =0.18+0.14 e^{-\Delta t / 420}+0.18 e^{-\Delta t / 70} \\
& +0.24 e^{-\Delta t / 21}+0.26 e^{-\Delta t / 3.4}
\end{aligned}
$$

According to this formula, for an instantaneous removal of carbon from (or release to) the atmosphere, $92 \%$ is still removed (or present) after 1 year, $64 \%$ after 10 years, $34 \%$ after 100 years, and $19 \%$ after 1000 years. This is a little confusing when compared with observations over 1960-2007 that the increase in atmospheric $\mathrm{CO}_{2}$ in a given year was only $\sim 50 \%$ of the total emissions that year. The discrepancy can be explained by the fact that in any given year, the natural land and ocean carbon sinks represent an integrated response to all previous years of emissions.

For completeness we note that the amount of carbon sequestered by a particular geoengineering activity can also decay over time, if the reservoir to which the carbon is added is not permanently isolated from the atmosphere. To account for this we can introduce the notion of a stored fraction, $s(\Delta t)$. Clearly for some sequestration options there will be multiple decay timescales, as there are for the atmosphere in Eq. (15). As a first approximation we can assume exponential decay of storage, with an e-folding timescale, $\tau$ :

$s(\Delta t)=e^{-\Delta t / \tau}$

Now consider a specific carbon cycle geoengineering scenario, $R(t)$, which starts in year $t_{s}$ and involves the removal of $\mathrm{CO}_{2}$ from the atmosphere as some function of time until it stops in year $t_{c}$ (here the removal flux is defined as positive). The amount of $\mathrm{CO}_{2}$ which has been removed from the atmosphere, $\Delta C_{\mathrm{atm}}$, at some future time, $t_{f}$, can be found by integrating (over the interval $t_{s}$ to $t_{c}$ ) the product of the removal function, its remaining stored fraction, and the remaining airborne fraction of that:

$$
\Delta C_{\mathrm{atm}}=-\int_{t_{s}}^{t_{c}} R(t) s\left(t_{f}-t\right) f\left(t_{f}-t\right) d t
$$

We solve this integral using Eqs. (15), (16) and three simple cases for $R(t)$ that have been presented in the literature: (a) constant removal, $R=a$, (b) linearly increasing removal with time, $R(t)=b\left(t-t_{s}\right)$, and (c) exponentially increasing removal with time, $R(t)=E_{0} e^{c(t-t s)}$ (see Appendix A). In general, we assume that the earliest time that a particular carbon cycle geoengineering activity could start is $t_{s}=2020$, although exceptions are made for some scenarios in the literature that start earlier. Unfortunately, information on the value of $\tau$ is lacking for some reservoirs, or they have multiple decay timescales. As we are seeking to quantify the maximum potential of each option, in the results presented we assume permanent sequestration, i.e. $s(\Delta t)=1$, thus simplifying the integrals (see Appendix A). For relatively short-lived storage reservoirs such as vegetation biomass this amounts to assuming that they will be continually replenished as they decay. For the most complex case of measures to increase deep ocean carbon storage we estimate the "sequestration flux" of carbon that crosses the depth of winter mixing and assume it is permanently stored on the timescales considered, whereas any additional carbon that is remineralised above this depth is assumed to be instantaneously returned to the atmosphere.

Now we turn to the choice of the reference trajectory of atmospheric $\mathrm{CO}_{2}$ with time, $\mathrm{CO}_{2}(t)$. Clearly this will be a complex function of time, determined by emissions and natural sinks. To minimise errors introduced by non-linear feedbacks in the carbon cycle (and for consistency with the formulation of Eq. (15) for relatively small perturbations), we consider as a baseline a strong mitigation scenario with minimum reference $\mathrm{CO}_{2}$ concentration at key times in the future. We pick out two medium-term time horizons, 2050 and 2100 , of particular interest to policy makers. In 2050, with strong mitigation, $\mathrm{CO}_{2}$ could be restricted to about $450 \mathrm{ppm}$ (Kharecha and Hansen, 2008) (although even linearly extrapolating the current concentration growth rate of $2 \mathrm{ppm} \mathrm{yr}^{-1}$ it will be close to $470 \mathrm{ppm}$ ). In 2100 , with strong mitigation (but without geoengineered "negative emissions"), $\mathrm{CO}_{2}$ could be restricted to about $500 \mathrm{ppm}$. Most studies considering a lower stabilisation target of $450 \mathrm{ppm}$, e.g. (Stern, 2006), have to invoke negative emissions to achieve it, with a recent exception (Kharecha and Hansen, 2008). For reference, without mitigation and with strong positive carbon cycleclimate feedbacks, $\mathrm{CO}_{2}$ could reach about $600 \mathrm{ppm}$ in 2050, rising to about $1000 \mathrm{ppm}$ in 2100 (Cox et al., 2000; Lenton, 2000; Friedlingstein et al., 2006). 
Over long (millennial) timescales, long after a given geoengineering activity has ceased, the increase in atmospheric $\mathrm{CO}_{2}$ will depend on cumulative emissions, $\Sigma C_{\text {emit }}$, minus the amount of carbon "permanently" sequestered by a given geoengineering option on this timescale, $\Sigma C_{\text {seq }}$, times the long term airborne fraction (i.e. the first term in Eq. 15), which we now call $f_{\text {final }}$. The radiative forcing effect of the geoengineering option can then be calculated from Eq. (12) by taking $\mathrm{CO}_{2 \text {,ref }}$ to be the expected concentration in the absence of geoengineering and $\mathrm{CO}_{2}$ to be the actual concentration, which gives:

$\mathrm{RF}_{\text {final }} \approx \beta \ln \left(\frac{\mathrm{CO}_{2,1800}+f_{\text {final }}\left(\Sigma C_{\text {emit }}-\Sigma C_{\text {seq }}\right) / k}{\mathrm{CO}_{2,1800}+f_{\text {final }} \Sigma C_{\text {emit }} / k}\right)$

According to Eq. (15), the airborne fraction shrinks towards $f_{\text {final }}=0.18$, and is 0.193 after 1000 years (i.e. around year 3000). However, an important caveat is that $f_{\text {final }}$ actually increases with the net amount of $\mathrm{CO}_{2}$ added to the ocean-atmosphere-land system, as a consequence of ocean carbonate chemistry and positive climate-carbon cycle feedbacks (Lenton, 2006). To get an estimate of how $f_{\text {final }}$ varies as a function of net carbon addition we find a good fit to numerical model results (Lenton, 2006) $(<1.5 \%$ error for 0 $5000 \mathrm{PgC}$ ), is given by:

$f_{\text {final }}=0.152 e^{0.000179 \Sigma C_{\text {added }}}$

where $\Sigma C_{\text {added }}=\Sigma C_{\text {emit }}$ in the reference case and $\Sigma C_{\text {added }}=\Sigma C_{\text {emit }}-\Sigma C_{\text {seq }}$ in the geoengineering case. In this numerical model (Lenton, 2006) the minimum airborne fraction is smaller than in Eq. (15) (Joos et al., 1996). However, even with strong mitigation, a realistic lower limit on cumulative emissions is $\Sigma C_{\text {emit }}=1000 \mathrm{PgC}$, which is roughly twice the emissions to date. Since 1800 , around $350 \mathrm{PgC}$ has been emitted from fossil fuel burning, and up to $165 \mathrm{PgC}$ from land-use change emissions. This gives $f_{\text {final }}=0.18$ consistent with our earlier assumptions.

Using Eq. (19) in (18), we find an interesting result; that although a given change in atmospheric $\mathrm{CO}_{2}$ has a greater impact on radiative forcing at lower concentrations of $\mathrm{CO}_{2}$ a given sequestration of carbon has a greater impact on atmospheric $\mathrm{CO}_{2}$ if total emissions of carbon are greater. The two effects approximately cancel such that a given permanent sequestration of carbon has roughly the same impact on radiative forcing regardless of the total emissions of carbon. To illustrate this, consider a no-mitigation scenario, where all conventional fossil fuel resources are assumed to be combusted between 1800 and 3000, giving cumulative $\mathrm{CO}_{2}$ emissions of order $\Sigma C_{\text {emit }}=5000 \mathrm{PgC}$ $(2336 \mathrm{ppm})$. The corresponding $f_{\text {final }}=0.372$, gives a reference $1147 \mathrm{ppm}$ in the atmosphere (roughly 4 times the pre-industrial level) and a corresponding radiative forcing of $7.58 \mathrm{~W} \mathrm{~m}^{-2}$. In contrast, in our strong mitigation scenario, with $\Sigma C_{\text {emit }}=1000 \operatorname{PgC}(467 \mathrm{ppm})$ and $f_{\text {final }}=0.182$, the final atmospheric concentration is $363 \mathrm{ppm}$ with a corresponding radiative forcing of $1.43 \mathrm{~W} \mathrm{~m}^{-2}$. For $100 \mathrm{PgC}$ permanently sequestered, in the strong mitigation case $\mathrm{CO}_{2}$ is lowered by $10 \mathrm{ppm}$, whereas in the no mitigation case $\mathrm{CO}_{2}$ is lowered by $32 \mathrm{ppm}$, but in both cases, $\mathrm{RF}_{\text {final }} \approx-0.15 \mathrm{~W} \mathrm{~m}^{-2}$. For $1000 \mathrm{PgC}$ permanently sequestered, in the strong mitigation case $\mathrm{RF}_{\text {final }} \approx-1.43 \mathrm{~W} \mathrm{~m}^{-2}$ (returning $\mathrm{CO}_{2}$ to $278 \mathrm{ppm}$ and completely cancelling the radiative forcing that would have occurred due to $1000 \mathrm{PgC}$ emissions), whereas in the no mitigation case $\mathrm{RF}_{\text {final }} \approx-1.54 \mathrm{~W} \mathrm{~m}^{-2}$ (due to lowering $\mathrm{CO}_{2}$ from $1147 \mathrm{ppm}$ to $859 \mathrm{ppm}$ ).

In the following, we offer upper estimates of the potential of different carbon cycle geoengineering options, concentrating on the time horizons of 2050, 2100 and 3000. To calculate intermediate timescale effects of particular geoengineering scenarios on atmospheric $\mathrm{CO}_{2}$, we use solutions to Eq. (17) (see Appendix A), and convert this to radiative forcing using Eq. (14) and lower limits on atmospheric $\mathrm{CO}_{2}$ at the time, consistent with strong mitigation. To estimate the long-term effects of different cumulative geoengineering activities, there are two options. For measures where reservoirs would not be saturated and activity is assumed to continue on the millennial timescale we use Eq. (17) with $t_{c}=t_{f}=3000$, and Eq. (14) assuming $\mathrm{CO}_{2 \text {,ref }}=363 \mathrm{ppm}$, i.e. strong mitigation. For measures where sequestration reservoirs could be filled well before 3000, we use Eqs. (18) and (19), together with estimates of their maximum potential long-term carbon storage, and total emissions corresponding to strong mitigation $(1000 \mathrm{PgC})$. We have also made calculations for a "no mitigation" $(5000 \mathrm{PgC})$ scenario but the long-term radiative forcing effects generally do not differ significantly. To calculate the intermediate timescale effects of a "no mitigation" scenario one should ideally take into account the fact that the airborne fraction increases significantly with increasing emissions (i.e. the terms in Eq. 15 change). Preliminary estimates and Eq. (14) suggest that the resulting radiative forcing effects will be similar to or less than we obtain assuming a strong mitigation scenario.

\section{Results}

The results are summarised in Table 1 for shortwave options and Table 2 for longwave $\left(\mathrm{CO}_{2}\right)$ options.

\subsection{Shortwave options}

\subsubsection{Sunshades in space}

To offset a doubled pre-industrial atmospheric concentration of $\mathrm{CO}_{2}$ is usually assumed to require a decrease in incoming solar radiation of roughly $1.8 \%$, e.g. (Govindasamy and Caldeira, 2000), which using Eq. (1) gives a radiative forcing of $\mathrm{RF}=-4.23 \mathrm{~W} \mathrm{~m}^{-2}$. However,the efficacy of changes in the solar constant is only $\sim 89 \%$ of that due to changes in $\mathrm{CO}_{2}$ (Hansen et al., 2005), because globally uniform shortwave forcing is biased to the lower latitudes where 
Table 1. Estimated radiative forcing potential of geoengineering options to alter planetary albedo. In common with the literature, for the first option, a back calculation is made of the albedo change required to counteract the radiative forcing due to doubling $\mathrm{CO}_{2}$, whereas for the remaining options, forward calculations are made of the maximum potential radiative forcing. The latter are based on upper limit albedo changes and areas suggested in the literature (see text). Calculations were done at full precision but outputs are generally given to 2 significant figures commensurate with our first order approach.

\begin{tabular}{|c|c|c|c|c|c|c|c|c|}
\hline Option & Area $\left(m^{2}\right)$ & $\begin{array}{l}\text { Fraction of } \\
\text { Earth } \\
f_{\text {Earth }}\end{array}$ & $\begin{array}{l}\text { Albedo change } \\
\text { within area } \Delta \alpha\end{array}$ & $\begin{array}{l}\text { Scaled albedo } \\
\text { change of layer }\end{array}$ & $\begin{array}{l}\text { Transmittance } \\
\text { factor } f_{a}\end{array}$ & $\begin{array}{l}\text { Planetary albedo } \\
\text { change } \Delta \alpha_{p}\end{array}$ & $\begin{array}{l}\text { Solar radiation } \\
\text { at TOA } \\
S_{0}\left(\mathrm{~W} \mathrm{~m}^{-2}\right)\end{array}$ & $\begin{array}{l}\text { Radiative forcing } \\
\mathrm{RF}\left(\mathrm{W} \mathrm{m}^{-2}\right)\end{array}$ \\
\hline Increase marine cloud albedo & & & & $\Delta \alpha_{a}$ & & & & \\
\hline Mechanical & $8.9 \times 10^{13}$ & 0.175 & 0.074 & 0.013 & 0.84 & 0.011 & 345 & -3.71 \\
\hline Biological & $5.1 \times 10^{13}$ & 0.1 & 0.008 & $0.000067^{*}$ & 0.84 & 0.000056 & 345 & -0.019 \\
\hline Increase land surface albedo & & & & $\Delta \alpha_{s}$ & & & & \\
\hline Desert & $1.0 \times 10^{13}$ & 0.02 & 0.44 & 0.0088 & 0.73 & 0.0064 & 330 & -2.12 \\
\hline Grassland & $3.85 \times 10^{13}$ & 0.075 & 0.0425 & 0.0032 & 0.48 & 0.0015 & 330 & -0.51 \\
\hline Cropland & $1.4 \times 10^{13}$ & 0.028 & 0.08 & 0.0022 & 0.48 & 0.0011 & 330 & -0.35 \\
\hline Settlements & $3.25 \times 10^{12}$ & 0.0064 & 0.15 & 0.00096 & 0.48 & 0.00046 & 330 & -0.15 \\
\hline Urban areas & $1.5 \times 10^{12}$ & 0.0029 & 0.1 & 0.00029 & 0.48 & 0.00014 & 330 & -0.047 \\
\hline
\end{tabular}

* Biological enhancement of cloud albedo is only applied for 1 month per year hence division by 12 .

Table 2. Estimated radiative forcing potential of carbon cycle geoengineering options. Effects are calculated relative to a strong mitigation scenario in which a total of $1000 \mathrm{PgC}$ are emitted and atmospheric $\mathrm{CO}_{2}$ (and corresponding radiative forcing) reaches $450 \mathrm{ppm}\left(2.58 \mathrm{~W} \mathrm{~m}{ }^{-2}\right.$ ) in 2050 , stabilises at $500 \mathrm{ppm}\left(3.14 \mathrm{~W} \mathrm{~m}^{-2}\right)$ in 2100 and then declines to $363 \mathrm{ppm}\left(1.43 \mathrm{~W} \mathrm{~m}^{-2}\right)$ on a millennial timescale.

\begin{tabular}{|c|c|c|c|c|c|c|c|}
\hline \multirow{2}{*}{ Geoengineering Option } & \multicolumn{2}{|c|}{2050} & \multicolumn{2}{|c|}{2100} & \multicolumn{3}{|c|}{3000} \\
\hline & $\Delta \mathrm{CO}_{2}(\mathrm{ppm})$ & $\mathrm{RF}\left(\mathrm{W} \mathrm{m}^{-2}\right)$ & $\Delta \mathrm{CO}_{2}(\mathrm{ppm})$ & $\mathrm{RF}\left(\mathrm{W} \mathrm{m}^{-2}\right)$ & $\Sigma C_{\text {seq }}(\mathrm{PgC})$ & $\Delta \mathrm{CO}_{2}(\mathrm{ppm})$ & $\mathrm{RF}_{\text {final }}\left(\mathrm{W} \mathrm{m}^{-2}\right)$ \\
\hline \multicolumn{8}{|l|}{ Enhance land carbon sink } \\
\hline $\begin{array}{l}\text { Afforestation } \\
\text { Bio-char production } \\
\text { Air capture and storage }\end{array}$ & $\begin{array}{l}-41 \\
-10 \\
-58\end{array}$ & $\begin{array}{l}-0.49 \\
-0.12 \\
-0.74\end{array}$ & $\begin{array}{l}-34 \\
-37 \\
-186\end{array}$ & $\begin{array}{l}-0.37 \\
-0.40 \\
-2.5\end{array}$ & $\begin{array}{l}183 \\
399 \\
>1000\end{array}$ & $\begin{array}{l}-16 \\
-34 \\
>|-85|\end{array}$ & $\begin{array}{l}-0.27 \\
-0.52 \\
>|-1.43|\end{array}$ \\
\hline \multicolumn{8}{|c|}{ Enhance ocean carbon sink } \\
\hline $\begin{array}{l}\text { Phosphorus addition } \\
\text { Nitrogen fertilisation } \\
\text { Iron fertilisation } \\
\text { Enhance upwelling } \\
\text { Enhance downwelling } \\
\text { Carbonate addition }\end{array}$ & $\begin{array}{l}-5.9 \\
-4.5 \\
-9.0 \\
-0.1 \\
-0.08 \\
-0.4 \\
\end{array}$ & $\begin{array}{l}-0.070 \\
-0.054 \\
-0.11 \\
-0.0017 \\
-0.00095 \\
-0.0048 \\
\end{array}$ & $\begin{array}{l}-12 \\
-9.3 \\
-19 \\
-0.3 \\
-0.18 \\
-2.3 \\
\end{array}$ & $\begin{array}{l}-0.13 \\
-0.10 \\
-0.20 \\
-0.0032 \\
-0.0019 \\
-0.025\end{array}$ & $\begin{array}{l}574 \\
299 \\
227 \\
16^{*} \\
9^{*} \\
251^{*}\end{array}$ & $\begin{array}{l}-52 \\
-25 \\
-19 \\
-1.9 \\
-1.1 \\
-30\end{array}$ & $\begin{array}{l}-0.83 \\
-0.38 \\
-0.29 \\
-0.028 \\
-0.016 \\
-0.46\end{array}$ \\
\hline
\end{tabular}

* Activities assumed to continue to year 3000 hence larger airborne fraction than for other ocean options.

positive climate feedbacks are weaker, whereas longwave forcing is more uniform, and in the higher latitudes there are stronger positive climate feedbacks. This explains why $\mathrm{RF}=-4.23 \mathrm{~W} \mathrm{~m}^{-2}$ from a $1.8 \%$ reduction in solar constant offsets $\mathrm{RF}=3.71 \mathrm{~W} \mathrm{~m}^{-2}$ from doubling $\mathrm{CO}_{2}$. If such a reduction in incoming solar radiation were achieved by placing a sunshade consisting of multiple flyers at the L1 point (Angel, 2006), it would require a total area of 4.7 million $\mathrm{km}^{2}$. The negative radiative forcing effect could be varied by altering the size of the sunshade. The calculations presented in the literature are based on a static radiative imbalance, however with the observed trends in emissions to date (Raupach et al., 2007) it is clear that the radiative imbalance is set to continue increasing. For example, if a sunshade was in place today at the L1 point to offset the current radiative imbalance, then given that atmospheric $\mathrm{CO}_{2}$ is rising at $2 \mathrm{ppm} \mathrm{yr}^{-1}$ and converting this to $0.0282 \mathrm{~W} \mathrm{~m}^{-2} \mathrm{yr}^{-1}$ using Eq. (13), a surface area of $\sim 35700 \mathrm{~km}^{2}$ would need to be added each year. This equates to $\sim 155000$ launches per year, each carrying 800000 space flyers of area $0.288 \mathrm{~m}^{2}$ (Angel, 2006). Thus, the area of shades or reflectors in space would need to increase significantly year on year to keep pace with the current rate of increase in radiative forcing. 


\subsubsection{Stratospheric aerosols}

To counteract the radiative forcing due to a doubling of atmospheric $\mathrm{CO}_{2}\left(3.71 \mathrm{~W} \mathrm{~m}^{-2}\right)$ by increasing the stratospheric reflection of shortwave radiation back to space, requires a sulphate aerosol optical depth of $\tau \sim 0.155$, according to Eq. (2) (Hansen et al., 2005). However, the efficacy of stratospheric (volcanic) aerosol forcing is estimated to be $\sim 91 \%$ from simulations of the aftermath of the Mt Pinatubo eruption (Hansen et al., 2005), and taking this into account suggests $\tau \sim 0.17$ is required to counteract the temperature effect of a doubling of $\mathrm{CO}_{2}$. This is comparable to the peak optical depth that occurred after the Mt Pinatubo eruption, although the resulting cooling was only partially realised because of the short lifetime of the aerosol and the thermal inertia of the ocean. Geoengineering approaches aim to continually replace the aerosol and thus to fully realise the resulting cooling and maintain it. The corresponding amount of sulphate required depends on the size of the particles and the location of injection, ranging from an estimated $1.5 \mathrm{TgS} \mathrm{yr}^{-1}$ (Rasch et al., 2008) to $5 \mathrm{TgS} \mathrm{yr}^{-1}$ (Crutzen, 2006; Wigley, 2006). This is a modest amount when compared with anthropogenic emissions of 55-68 $\mathrm{TgS} \mathrm{yr}^{-1}$ (in 2000) from burning fossil fuels (Smith et al., 2001; Stern, 2005). Smaller particles (radius $\sim 0.1 \mu \mathrm{m}$ ) are more effective because they have no impact in the longwave, while the larger, volcanic-like particles absorb and emit in the longwave (Stenchikov et al., 1998). Recent work finds an optimal effective radius for cooling by sulphate aerosol of $0.23 \mu \mathrm{m}$ (Lacis et al., 2009). However, the tendency of sulphate aerosol particles to coagulate will reduce their radiative effectiveness and hasten their exit from the stratosphere (and if they grow in excess of $\sim 2.2 \mu \mathrm{m}$ they become net warming agents) (Lacis et al., 2009). The residence time and spatial spread of particles in the stratosphere varies greatly with the location of injection (Crutzen, 2006; Wigley, 2006; Rasch et al., 2008). Residence time and global coverage is maximised when injections occur into the lower stratosphere over the tropics (Oman et al., 2005; Robock et al., 2008).

If soot aerosols (Crutzen, 2006; Lacis et al., 2009) or manufactured aluminium particles (Teller et al., 1997, 2002) are used instead of sulphate aerosol, the required mass loading could potentially be reduced by orders of magnitude. Stratospheric soot aerosols are only effective as a net cooling agent at high stratospheric altitude, e.g. $44-50 \mathrm{~km}$, where an optical depth $\tau=0.01$ (at $0.55 \mu \mathrm{m}$ ), could achieve an estimated $\mathrm{RF}=-1.86 \mathrm{~W} \mathrm{~m}^{-2}$ (Lacis et al., 2009). For aluminium aerosols of optical depth $\tau=0.01$ (at $0.55 \mu \mathrm{m}$ ), the adjusted forcing ranges from $\mathrm{RF} \sim-0.5 \mathrm{~W} \mathrm{~m}^{-2}$ for deployment at the bottom of the stratosphere toward $\mathrm{RF} \sim-1 \mathrm{~W} \mathrm{~m}^{-2}$ for deployment at $50 \mathrm{~km}$ altitude (Lacis et al., 2009).

\subsubsection{Increase cloud albedo - mechanical}

Marine stratiform cloud albedo could be globally increased by the mechanical generation of sea salt spray as a source of cloud condensation nuclei (CCN) (Latham, 1990). It has been argued that a $50-100 \%$ increase in droplet concentration in all marine stratiform clouds would give rise to an increase in top-of-cloud albedo of 0.02 , causing a planetary albedo increase of 0.005 , and that this would offset a doubling of atmospheric $\mathrm{CO}_{2}$ (Latham, 2002; Bower et al., 2006). However, an increase in planetary albedo of 0.005 gives a TOA radiative forcing of $-1.71 \mathrm{~W} \mathrm{~m}^{-2}$ from Eq. (3), sufficient to offset the present anthropogenic radiative forcing, but not that from a doubling of $\mathrm{CO}_{2}$, as noted in the original source (Charlson et al., 1987). To offset $3.71 \mathrm{~W} \mathrm{~m}^{-2}$ from doubling $\mathrm{CO}_{2}$ requires a planetary albedo increase of 0.011 (Latham et al., 2008). Furthermore, the original conversion from changes in top-of-cloud albedo to planetary albedo assumed $30 \%$ global coverage of marine stratiform clouds (i.e. $42 \%$ coverage over the ocean). Recently this has been revised, considering non-overlapped marine stratiform clouds to cover $17.5 \%$ of the Earth's surface, a required change in top-of-cloud albedo of 0.062 is estimated (Latham et al., 2008). However, the revised calculation assumes that the change in low-level cloud albedo causes an identical change in planetary albedo, which would be wrong even if the clouds were at the top of the atmosphere. Instead they are near the surface and the change in planetary albedo will be at most $f_{a} \sim 0.84$ of the change in top-of-cloud albedo (see Sect. 2.1). Accounting for this, the required increase in top-of-cloud albedo is 0.074 (Table 1) across all regions of marine stratiform clouds. This is a markedly larger value than the often cited 0.02 , but not inconceivable given that such clouds typically range in albedo from 0.3 to 0.7 . The efficacy of cloud albedo changes is $\sim 100 \%$ (Hansen et al., 2005) so there is no need to adjust for that. However, a further caveat is that the fraction of the sky covered by marine stratifrom clouds is assumed to be $100 \%$ over the $17.5 \%$ of the Earth's surface considered, which is not supported by observations (Fairall et al., 1990).

To achieve a 0.074 increase in top-of-cloud albedo, would require at least a 3 fold increase in aerosol number concentration (or a 2.2 fold increase in cloud droplet number concentration) (Sect. 2.1). This is comparable to the 2.3 fold increase in cloud droplet number concentration suggested elsewhere (Latham et al., 2008), and well within the range of up to a 10 -fold increase argued to be technically feasible. However, if for example the power determining the proportion of added aerosol converted to new cloud condensation nuclei falls below $\gamma \sim 1 / 3$ the required change in albedo would become unachievable. 


\subsubsection{Increase cloud albedo - biological}

An alternative proposal to enhance marine stratiform cloud albedo is to increase the biological source of $\mathrm{CCN}$ from dimethyl sulphide (DMS) emissions (Charlson et al., 1987) by iron fertilising several small patches of the Southern Ocean for one month in summer (Wingenter et al., 2007). It has been estimated that this could generate a $10 \%$ increase in total CCN over the entire Southern Ocean $(\sim 10 \%$ of the Earth's surface) and a corresponding increase in cloud albedo by 0.008 (Wingenter et al., 2007), in agreement with the analysis in Sect. 2.1. This was argued to be capable of causing a regional, seasonal radiative forcing of $\sim 3 \mathrm{~W} \mathrm{~m}^{-2}$ (Wingenter et al., 2007), but this wrongly assumes the change in low-level cloud albedo causes an identical change in planetary albedo. Assuming $f_{a} \sim 0.84$ and scaling by fraction of the year as well as fraction of the Earth's surface affected gives $\Delta \alpha_{p}=0.000056$, and assuming the mean incident radiation over ocean, an annual global mean $\mathrm{RF}=-0.019 \mathrm{~W} \mathrm{~m}^{-2}$ (Table 1). This does not factor in that the TOA solar radiation over the Southern Ocean in summer $\left(\sim 400 \mathrm{~W} \mathrm{~m}^{-2}\right)$ is slightly more than the annual mean over the ocean as a whole. Yet it is probably a significant overestimate as the increase in CCN over the Southern Ocean has subsequently been revised downwards to $2.6 \%$ (Vogt et al., 2008) or 1.4\% (Woodhouse et al., 2008), which give corresponding cloud albedo increases of 0.0021 or 0.0012 and a factor of 4 to 7 reduction in radiative forcing.

\subsubsection{Increase desert albedo}

It has been suggested at a meeting at the US Department of Energy (Gaskill, 2004) that increasing the albedo of global desert areas (up to $1.16 \times 10^{13} \mathrm{~m}^{2}$ deemed suitable) could counteract a significant amount of radiative forcing. These land areas are suggested because they are largely uninhabited, sparsely vegetated, flat and stable (aeolian deserts are excluded). Such deserts typically have an albedo in the range 0.2 to 0.5 , depending on geologic composition (Tsvetsinskaya et al., 2002). An albedo increase from 0.36 to 0.8 has been proposed (Gaskill, 2004), with the addition of a reflective surface, made of white polyethylene top surface and an aluminium bottom surface. The application of this to $2 \%$ of Earth's surface $\left(1.0 \times 10^{13} \mathrm{~m}^{2}\right)$ has been estimated to give $-2.75 \mathrm{~W} \mathrm{~m}^{-2}$ radiative forcing (Gaskill, 2004). Deserts generally have higher incident solar radiation than the mean over land, so to compensate for this we assume clear skies $\left(f_{a}=0.73\right)$, which gives $\mathrm{RF}=-2.12 \mathrm{~W} \mathrm{~m}^{-2}$ (Table 1). Mean all sky conditions over land $\left(f_{a}=0.48\right)$ would give $\mathrm{RF}=-1.45 \mathrm{~W} \mathrm{~m}^{-2}$. The mean solar zenith angle over deserts is generally less than the global average, which would tend to increase the RF estimates. The cooling effect of this option would clearly be biased to the regions altered.

\subsubsection{Increase grassland albedo}

Variegated plants, light shrubs or bioengineered grasses and shrubs could be used to increase the albedo of grassland, open shrubland and savannah globally by an estimated 0.0425 (25\%) from 0.17 (Hamwey, 2007). Using a 2-D surface radiation balance model an increase in global annual average surface albedo of $\Delta \alpha_{s}=0.002626$ and surface $\mathrm{RF}=-0.59 \mathrm{~W} \mathrm{~m}^{-2}$ are estimated (Hamwey, 2007), implying an average downward solar radiation flux at the altered surfaces of $225 \mathrm{~W} \mathrm{~m}^{-2}$. However, the method fails to account for absorption of the reflected radiation before it leaves the atmosphere, which assuming $T_{a}=0.854$ (exit through a clear sky) gives a revised TOA $\mathrm{RF}=-0.50 \mathrm{~W} \mathrm{~m}^{-2}$. We use the total area of grassland, open shrubland and savannah from the IGBP-DIS land cover dataset (Loveland et al., 2000) to estimate $\Delta \alpha_{s}=0.0032$, which assuming $f_{a}=0.48$ and the mean incident radiation over land gives $\mathrm{RF}=-0.51 \mathrm{~W} \mathrm{~m}^{-2}$ (Table 1). Existing results (Hamwey, 2007) suggest this probably underestimates the shortwave radiation reaching grassland surfaces. Assuming that is $225 \mathrm{~W} \mathrm{~m}^{-2}$ on average and $T_{a}=0.854$ of the reflected radiation leaves the atmosphere would give $\mathrm{RF}=-0.61 \mathrm{~W} \mathrm{~m}^{-2}$.

\subsubsection{Increase cropland albedo}

A similar proposal addresses croplands and assumes a default increase in maximum canopy albedo by $0.04(20 \%)$ from 0.2 (Ridgwell et al., 2009). The area of croplands is considerably greater in the IGBP-DIS (Loveland et al., 2000) than the UMd (Hansen et al., 2000) land cover dataset $\left(1.4 \times 10^{13} \mathrm{~m}^{2}\right.$ versus $\left.1.11 \times 10^{13} \mathrm{~m}^{2}\right)$, giving a range in $\Delta \alpha_{s}=0.00087-0.0011$, which assuming the mean incident radiation over land and $f_{a}=0.48$ gives a range in $\mathrm{RF}=-0.14$ to $-0.17 \mathrm{~W} \mathrm{~m}^{-2}$. However, a 0.08 increase in maximum canopy albedo is argued to be feasible (Ridgwell et al., 2009), which together with the upper area estimate, would give $\mathrm{RF}=-0.35 \mathrm{~W} \mathrm{~m}^{-2}$ (assuming the crops are present year-round). This proposal has been assessed in a coupled atmosphere-ocean model (HadCM3) with a dynamic global vegetation model (TRIFFID), designating areas of cropland in which only $\mathrm{C}_{3}$ or $\mathrm{C}_{4}$ grasses are allowed to grow, but not explicitly representing cropping (Ridgwell et al., 2009). For a maximum change in canopy albedo of 0.08 , a global mean surface temperature change of $-0.213 \pm 0.083^{\circ} \mathrm{C}$ is predicted relative to a control run with $700 \mathrm{ppm} \mathrm{CO}_{2}$. Given a climate sensitivity parameter for this model of $\lambda=0.89^{\circ} \mathrm{C} \mathrm{W}^{-1} \mathrm{~m}^{2}$ (IPCC, 2007) this suggests a radiative forcing of $\mathrm{RF}=-0.24 \pm 0.09 \mathrm{~W} \mathrm{~m}^{-2}$ was generated in the model experiment, considerably less than our estimate. The reasons include that the actual canopy albedo change was on average less than the maximum 0.08 , the canopy was sometimes covered by snow anyway, and changes in cloud cover sometimes tended to counteract the imposed surface albedo changes (A. Ridgwell, personal communication, 
2009). In reality, crops would only be present for part of the year, reducing the radiative forcing. Thus, our estimate of $\mathrm{RF}=-0.35 \mathrm{~W} \mathrm{~m}^{-2}$ is a generous upper limit (Table 1). It is more than the effect of all historical land use change, estimated at $\mathrm{RF}=-0.24 \mathrm{~W} \mathrm{~m}^{-2}$ (Betts et al., 2007).

\subsubsection{Increase human settlement albedo}

Albedo enhancement measures could potentially be applied to all areas of human settlement (Hamwey, 2007). A per capita value of $500 \mathrm{~m}^{2}$ of human settlement has been assumed (Hamwey, 2007), and using 2005 global population data this gives a settled area of $0.64 \%$ of the Earth's surface (or $2.3 \%$ of the land surface). This area is assumed to have an albedo of 0.15 , appropriate for the composite surface albedo of urban regions (Jin et al., 2005; Taha, 2008), and it is assumed it can be doubled to 0.3 (Hamwey, 2007). Using a 2-D surface radiation balance model a change in global surface albedo of $\Delta \alpha_{s}=0.000875$ and $\mathrm{RF}=-0.17 \mathrm{~W} \mathrm{~m}^{-2}$ are estimated (Hamwey, 2007), implying an average downward solar radiation flux at the altered surfaces of $194 \mathrm{~W} \mathrm{~m}^{-2}$. However, the method fails to account for absorption of the reflected radiation before it leaves the atmosphere, which assuming $T_{a}=0.854$ (exit through a clear sky) gives a revised $\mathrm{RF}=-0.15 \mathrm{~W} \mathrm{~m}^{-2}$. Using the same area and our global approach, we obtain $\Delta \alpha_{s}=0.00096$, which assuming $f_{a}=0.48$ and the mean incident radiation over land also gives $\mathrm{RF}=-0.15 \mathrm{~W} \mathrm{~m}^{-2}$ (Table 1 ). This probably slightly underestimates the shortwave radiation reaching human settlement surfaces. Assuming that is $194 \mathrm{~W} \mathrm{~m}^{-2}$ on average and $T_{a}=0.854$ of the reflected radiation leaves the atmosphere would give $\mathrm{RF}=-0.16 \mathrm{~W} \mathrm{~m}^{-2}$.

\subsubsection{Increase urban albedo}

The albedo of urban regions can be increased by using highly reflective roofs and altering the material used in paving roads (Rosenfeld et al., 1997; Akbari et al., 2009). Assuming roofs comprise $25 \%$ of urban area and can have their albedo increased by 0.25 , and paved surfaces comprise $35 \%$ of urban area and can have their albedo increased by 0.15 , the average increase in albedo of urban areas would be 0.1 (Akbari et al., 2009). Assuming 1\% of the land surface $\left(1.5 \times 10^{12} \mathrm{~m}^{2}\right)$ is urban this has been estimated to induce a radiative forcing of $-0.044 \mathrm{~W} \mathrm{~m}^{-2}$ (Akbari et al., 2009). Using the same $\Delta \alpha_{s}=0.000294$, the mean incident radiation over land and $f_{a}=0.48$, we estimate $\mathrm{RF}=-0.047 \mathrm{~W} \mathrm{~m}^{-2}$ (Table 1). However, satellite observations suggest the actual global urban area may be far less than assumed (Akbari et al., 2009) at $2.6 \times 10^{11} \mathrm{~m}^{2}$ (Hansen et al., 2000; Loveland et al., 2000 ) or $0.051 \%$ of the Earth's surface, which with $f_{a}=0.48$ and the mean incident solar radiation over land would give $\mathrm{RF}=-0.0081 \mathrm{~W} \mathrm{~m}^{-2}$.

Atmos. Chem. Phys., 9, 5539-5561, 2009

\subsection{Longwave $\left(\mathrm{CO}_{2}\right)$ options}

\subsubsection{Afforestation and reforestation}

The most optimistic estimates suggest that $120 \mathrm{PgC}$ could be accumulated by afforestation and reforestation by 2035 (Read and Parshotam, 2007; Read, 2008), assuming a linear increase in removal (at $b=0.4 \mathrm{PgC} \mathrm{yr}^{-2}$ ) from $0 \mathrm{PgC} \mathrm{yr}^{-1}$ in 2010 to $9.6 \mathrm{PgC} \mathrm{yr}^{-1}$ in 2034 , i.e. around four times the current land carbon sink. This is followed by the accumulation a further $63 \mathrm{PgC}$ in standing plantations by 2060 (i.e. $183 \mathrm{PgC}$ in total), at a constant rate of $a=2.52 \mathrm{PgC} \mathrm{yr}^{-1}$. It is assumed that there is no decay of the biomass reservoir on this timescale. Following this scenario, we calculate $79 \mathrm{PgC}(37 \mathrm{ppm})$ would have been removed from the atmosphere in $2035,88 \mathrm{PgC}(41 \mathrm{ppm})$ in 2050 giving $\mathrm{RF}(2050) \approx-0.49 \mathrm{~W} \mathrm{~m}^{-2}$, and $94 \mathrm{PgC}(44 \mathrm{ppm})$ in 2060 , showing a saturation of the effect. Given that the $183 \mathrm{PgC}$ stored in plantation biomass in 2060 exceeds estimates of the total amount of carbon that has been lost to date due to land use change (Houghton, 2008) (much of it from soil), it is not clear that it could be increased further. It has separately been estimated that $192 \mathrm{PgC}$ could be accumulated in 50 years (Leake, 2008) but other sources give only 50$100 \mathrm{PgC}$ (Winjum et al., 1992). Holding the $183 \mathrm{PgC}$ store constant to 2100 (i.e. no further uptake or decay) causes the effect on the atmosphere to decay to $73 \mathrm{PgC}$ ( $34 \mathrm{ppm}$ ), with $\mathrm{RF}(2100) \approx-0.37 \mathrm{~W} \mathrm{~m}^{-2}$. Assuming strong mitigation, $35 \mathrm{PgC}(16 \mathrm{ppm})$ are removed from the atmosphere in 3000 and $\mathrm{RF}_{\text {final }} \approx-0.27 \mathrm{~W} \mathrm{~m}^{-2}$.

\subsubsection{Bio-char production}

It has been estimated that up to $0.56 \mathrm{PgC} \mathrm{yr}^{-1}$ of bio-char could be produced at present and that this could be significantly increased by up-scaling biomass energy production (Lehmann et al., 2006). One scenario for bio-char production suggests $15.6 \mathrm{PgC}$ could be stored by 2035 and $52 \mathrm{PgC}$ by 2060 , increasing linearly at $b=0.048 \mathrm{PgC} \mathrm{yr}^{-2}$ from $0 \mathrm{PgC} \mathrm{yr}^{-1}$ in 2010 to $1.2 \mathrm{PgC} \mathrm{yr}^{-1}$ in 2035 and then exponentially at $c=1.5 \% \mathrm{yr}^{-1}$ to $1.74 \mathrm{PgC} \mathrm{yr}^{-1}$ in 2060 , i.e. approaching the size of the current land carbon sink (Read and Parshotam, 2007; Read, 2008). Assuming there is no decay of the charcoal carbon on this timescale, we calculate $11 \mathrm{PgC}(5 \mathrm{ppm})$ would have been removed from the atmosphere in $2035,22 \mathrm{PgC}(10 \mathrm{ppm})$ in 2050 giving $\mathrm{RF}(2050) \approx-0.12 \mathrm{~W} \mathrm{~m}^{-2}$, and $31 \mathrm{PgC}(14 \mathrm{ppm})$ in 2060. There is scope to further scale-up this geoengineering option, according to estimates that if projected renewable energy demand in 2100 were met entirely through pyrolysis, up to 5.5-9.5 $\mathrm{PgC} \mathrm{yr}^{-1}$ of bio-char could be produced (Lehmann et al., 2006). Continuing the exponential trend forward gives $3.15 \mathrm{PgC} \mathrm{yr}^{-1}$ in 2100 , a total bio-char reservoir of $148 \mathrm{PgC}$ and a corresponding removal from the atmosphere of $79 \mathrm{PgC}(37 \mathrm{ppm})$ giving $\mathrm{RF}(2100) \approx-0.40 \mathrm{~W} \mathrm{~m}^{-2}$. In the 
long term, the bio-char storage capacity of global cropland is estimated at $224 \mathrm{PgC}$ and for temperate grasslands $175 \mathrm{PgC}$, i.e. $\sim 400 \mathrm{PgC}$ in total (or a $\sim 25 \%$ increase in global soil carbon). Assuming that as it decays, this reservoir is continually refilled, the long-term potential is $\mathrm{RF}_{\text {final }} \approx-0.52 \mathrm{~W} \mathrm{~m}^{-2}$, which in the strong mitigation scenario is due to a $34 \mathrm{ppm}$ reduction in $\mathrm{CO}_{2}$.

\subsubsection{Air capture and storage}

Bio-energy with carbon storage (BECS) is estimated to have a better cost-benefit ratio than air capture with sodium hydroxide (Keith et al., 2006). An optimistic estimate is that with $\mathrm{CO}_{2}$ sequestration from fermentation starting in 2020 and $\mathrm{CO}_{2}$ capture from flue gases in 2025 , up to $50 \mathrm{PgC}$ could be sequestered by 2035 and a massive $298 \mathrm{PgC}$ by 2060 (Read and Parshotam, 2007; Read, 2008). These figures assume that bio-fuels displace oil as the major transport fuels equivalent to $8.4 \mathrm{PgC} \mathrm{yr}^{-1}$ in 2035 and $12.2 \mathrm{PgC} \mathrm{yr}^{-1}$ in 2060, and biomass burning displaces a significant amount of the coal used in electricity production equivalent to 4.2 $\mathrm{PgC} \mathrm{yr}^{-1}$ in 2035 and $6.1 \mathrm{PgC} \mathrm{yr}^{-1}$ in 2060. (These displacements are not considered here as they amount to mitigation.) Taking this scenario as an upper estimate we calculate that $124 \mathrm{PgC}(58 \mathrm{ppm})$ would have been removed from the atmosphere in 2050 , with $\mathrm{RF}(2050) \approx-0.74 \mathrm{~W} \mathrm{~m}^{-2}$. Having reached such a high level, activity would be unlikely to just stop after 2060. Assuming sequestration remains constant at $11.8{\mathrm{PgC} \mathrm{yr}^{-1}}^{-1}$ until 2100 , a massive $771 \mathrm{PgC}$ would be sequestered causing a $399 \mathrm{PgC}(186 \mathrm{ppm})$ atmospheric reduction and $\operatorname{RF}(2100) \approx-2.5 \mathrm{~W} \mathrm{~m}^{-2}$. Alternatively, chemical air capture with storage, using e.g. sodium hydroxide and lime, could potentially generate whatever size of carbon sink societies were willing to pay for, as it is unlikely to be limited by available substrates or land surface area (Keith et al., 2006). Ultimately the amount of $\mathrm{CO}_{2}$ sequestered may be limited by the size of available geologic reservoirs, but their storage capacity is estimated to exceed available fossil fuel resources (IPCC, 2005; House et al., 2006). In the long term, air capture and storage activity appears to have the potential to sequester $>1000 \mathrm{PgC}$ and cancel the total emissions from a strong mitigation scenario, i.e. $\mathrm{RF}_{\text {final }} \approx-1.43 \mathrm{~W} \mathrm{~m}^{-2}$, and more.

\subsubsection{Generic considerations for ocean fertilization}

A suite of geoengineering proposals seek to generate a sink of atmospheric $\mathrm{CO}_{2}$ by enhancing the biological pump of carbon from surface waters to the deep ocean. Carbon fixed by photosynthesising organisms in the surface ocean comes from dissolved inorganic carbon (DIC) in the water, creating a deficit of DIC that in turn drives an air-sea flux of $\mathrm{CO}_{2}$. Much of the resulting organic carbon is recycled back to DIC by heterotrophic organisms in the upper ocean, nullifying the effect on atmospheric $\mathrm{CO}_{2}$. However, a modest fraction escapes respiration and sinks to the deep ocean. A critical consideration is below what depth would geoengineered increases in the biological pump lead to an increase in net $\mathrm{CO}_{2}$ uptake?

The sinking flux of carbon decays away with depth due to remineralisation, approximating a power law function (Martin et al., 1987), although the power is now known to vary significantly with surface community structure (Buesseler et al., 2007). The "export flux" refers to the flux of carbon sinking out of the sunlit photic zone. A recent model mean gives this as $17 \mathrm{PgC} \mathrm{yr}^{-1}$ globally at $75 \mathrm{~m}$ (Najjar et al., 2007), but the bottom of the photic zone is more typically taken to be $100 \mathrm{~m}$ where $11 \mathrm{PgC} \mathrm{yr}^{-1}$ has been estimated (Laws et al., 2000; Gehlen et al., 2006). However, what is critical for long term carbon storage is the "sequestration flux" below the depth of winter wind-driven mixing, which ranges over 200-1000 m, depending on location (Lampitt et al., 2008). Any organic carbon remineralised to DIC above the depth of winter mixing will not create a DIC deficit on the annual or longer timescale and hence will not drive a $\mathrm{CO}_{2}$ sink. If we take $500 \mathrm{~m}$ as a reference depth, there the global sequestration flux is estimated to be in the range $2.3-5.5 \mathrm{PgC} \mathrm{yr}^{-1}$ (i.e. 20-50\% of the export flux at $100 \mathrm{~m}$ ) (Buesseler et al., 2007), with a long-favoured formula (Martin et al., 1987) giving $2.8 \mathrm{PgC} \mathrm{yr}^{-1}$ (i.e. $25 \%$ of the export flux). For upper limit estimates we assume a sequestration flux that is $50 \%$ of the change in export flux (unless otherwise stated).

The sequestration flux is ultimately controlled by the supply of essential nutrients to the surface ocean, including the macro-nutrients nitrogen $(\mathrm{N})$ and phosphorus $(\mathrm{P})$, and the micro-nutrient iron $(\mathrm{Fe})$. Hence ocean fertilisation proposals focus on adding new nutrient to the surface ocean or increasing nutrient supply from depth. However, relieving a deficit of one nutrient is likely to lead to limitation by another. In addition to $\mathrm{N}, \mathrm{P}$ and $\mathrm{Fe}$ limitation, silicate ( $\mathrm{Si}$ ) limitation is a possibility, especially for diatoms.

\subsubsection{Phosphorus addition to the ocean}

Humans already mine and add to the land surface $0.39-0.45 \times 10^{12} \mathrm{~mol} \mathrm{Pyr}^{-1}$ which has increased the riverine flux of biologically-available (dissolved and particulate) phosphorus (including sewage and detergent) to coastal seas by $0.31 \times 10^{12} \mathrm{~mol} \mathrm{P} \mathrm{yr}^{-1}$, suggesting a $70-80 \%$ transfer efficiency (Mackenzie et al., 2002). Some of this $\mathrm{P}$ input is converted to organic carbon in coastal and shelf seas and buried in their sediments with a minimum burial ratio of $\mathrm{C}: \mathrm{P} \sim 250$ (Lenton and Watson, 2000). In the North Sea this sediment burial flux of $\mathrm{P}$ is around $20 \%$ of the estimated anthropogenic $\mathrm{P}$ input (Brion et al., 2004). Extrapolating these figures to global coastal regions we estimate $0.18 \mathrm{PgC} \mathrm{yr}^{-1}$ is being sequestered in their sediments at present. If the remaining $80 \%$ of anthropogenic $\mathrm{P}$ inputs are transferred to the open ocean and go to fuel export production there, with half of this flux contributing to long-term sequestration below $500 \mathrm{~m}$, then a 
further sink of $0.16 \mathrm{PgC} \mathrm{yr}^{-1}$ is being generated at present, giving a total of $0.34 \mathrm{PgC} \mathrm{yr}^{-1}$. Alternatively, if all anthropogenic $\mathrm{P}$ loading ends up in the open ocean (none is buried in coastal and shelf sea sediments) then the estimated sequestration flux is $0.20 \mathrm{PgC} \mathrm{yr}^{-1}$ at present.

It has been suggested that mined phosphate could also be directly added to the surface ocean (Lampitt et al., 2008), potentially increasing the conversion efficiency to organic carbon. Regardless of whether this happens, we can expect inadvertent phosphorus additions to increase in future, one projection giving a linear increase to $0.42 \times 10^{12} \mathrm{~mol} \mathrm{P} \mathrm{yr}^{-1}$ in 2035 (Mackenzie et al., 2002), which could drive a sink of $0.27-0.47 \mathrm{PgC} \mathrm{yr}^{-1}$. Extrapolating the linear trend forwards gives $0.64 \times 10^{12} \mathrm{~mol} \mathrm{P} \mathrm{yr}^{-1}$ added to the ocean in 2100 driving $0.41-0.71 \mathrm{PgC} \mathrm{yr}^{-1}$. For the upper estimate, we calculate $13 \mathrm{PgC}(5.9 \mathrm{ppm})$ removed from the atmosphere in 2050 giving $\mathrm{RF}(2050) \approx-0.070 \mathrm{~W} \mathrm{~m}^{-2}$, and $26 \mathrm{PgC}(12 \mathrm{ppm})$ removed in 2100 giving $\mathrm{RF}(2100) \approx-0.13 \mathrm{~W} \mathrm{~m}^{-2}$. On the millennial timescale, the total reservoir of mineable phosphate of $323-645 \times 10^{12} \mathrm{~mol} P$ could readily be drained. Taking the upper estimate of the reservoir size, if $70 \%$ were to end up in bio-available form in the ocean and be converted to organic matter with $\mathrm{C}: \mathrm{P}=106$ it would sequester $574 \mathrm{PgC}$ giving $\mathrm{RF}_{\text {final }} \approx-0.83 \mathrm{~W} \mathrm{~m}^{-2}$, due to removing $112 \mathrm{PgC}(52 \mathrm{ppm})$ in our strong mitigation scenario. This assumes that nitrogen fixation will cause nitrogen availability in the ocean to track increased phosphorus availability (Redfield, 1958; Lenton and Watson, 2000) and that micro-nutrients (e.g. iron) do not limit new production in the regions to which phosphate is added.

\subsubsection{Alleviating nitrogen limitation}

There is a deficit of available nitrogen relative to phosphorus in the world ocean, of on average $2.7 \mu \mathrm{mol} \mathrm{kg}-1$ (Anderson and Sarmiento, 1994), compared to an average deep ocean nitrate concentration of $30.9 \mu \mathrm{mol} \mathrm{kg}^{-1}$. This deficit is maintained by negative feedbacks involving the processes of nitrogen fixation and denitrification (Lenton and Watson, 2000), but it might be at least partly removed by alleviating iron (Falkowski, 1997) and/or phosphorus (Karl and Letelier, 2008) limitation of nitrogen fixation in low-nutrient low-chlorophyll (LNLC) regions (Lampitt et al., 2008). Removing the nitrogen deficit would result in a $\sim 9 \%(2.7 / 30.9)$ increase in the export flux, corresponding to about $1 \mathrm{PgC} \mathrm{yr}^{-1}$ at $100 \mathrm{~m}$ depth. However, it is the sequestration flux below $\sim 500 \mathrm{~m}$ depth which is critical and an upper limit for the increase in that is $0.50 \mathrm{PgC} \mathrm{yr}^{-1}$. Using $0.5 \mathrm{PgC} \mathrm{yr}^{-1}$ as the upper limit for potential long-term sequestration due to global nitrogen fertilisation and starting at this constant level in 2020, then in 2050, 9.7 $\mathrm{PgC}(4.5 \mathrm{ppm})$ could be removed from the atmosphere and $\mathrm{RF}(2050) \approx-0.054 \mathrm{~W} \mathrm{~m}^{-2}$, which in 2100 increases to $20 \mathrm{PgC}(9.3 \mathrm{ppm})$ and $\mathrm{RF}(2100) \approx-0.10 \mathrm{~W} \mathrm{~m}^{-2}$. In the long term, if the whole deficit of nitrogen in the global ocean could be removed and converted to carbon, assuming an ocean volume of $1.36 \times 10^{18} \mathrm{~m}^{3}$, a density of $1027 \mathrm{~kg} \mathrm{~m}^{-3}$ and a Redfield ratio of $\mathrm{C}: \mathrm{N} \sim 6.6$, an additional $299 \mathrm{PgC}$ might be stored in the deep ocean. However, at $0.5 \mathrm{PgC} \mathrm{yr}^{-1}$ it would take 600 years to achieve an additional $300 \mathrm{PgC}$ of deep ocean storage. If this could be realised, then on the millennial timescale $\mathrm{RF}_{\text {final }} \approx-0.38 \mathrm{~W} \mathrm{~m}^{-2}$, due to removing $54 \mathrm{PgC}$ $(25 \mathrm{ppm})$ in our strong mitigation scenario.

\subsubsection{Ocean iron fertilisation}

A number of model studies have assessed the potential carbon sink that could be generated by iron fertilisation of different high-nutrient low-chlorophyll (HNLC) areas of the world ocean (Zeebe and Archer, 2005; Aumount and Bopp, 2006; Jin et al., 2008). The maximum potential is indicated by simulations that remove iron limitation globally for 100 years in a model run forced with SRES A2 emissions (Aumount and Bopp, 2006). Global export production across $100 \mathrm{~m}$ is increased initially by $3.5 \mathrm{PgC} \mathrm{yr}^{-1}$, decaying after 100 years to $1.8 \mathrm{PgC} \mathrm{yr}^{-1}$, and totalling $226 \mathrm{PgC}$. This causes a $33 \mathrm{ppm}$ reduction in atmospheric $\mathrm{CO}_{2}$ from $\sim 800 \mathrm{ppm}$, equivalent to $\mathrm{RF} \approx-0.22 \mathrm{~W} \mathrm{~m}^{-2}$. Diatoms are predicted to make a greater contribution to export production, creating fast sinking particles that should maximise the sequestration flux. If we take the predicted time mean increase in export flux across $100 \mathrm{~m}$ of $2.26 \mathrm{PgC} \mathrm{yr}^{-1}$, and liken the remineralisation with depth to that at a station where diatoms dominate (K2 in the Northwest Pacific) (Buesseler et al., 2007), then we estimate an increase in sequestration flux across $500 \mathrm{~m}$ of $1 \mathrm{PgC} \mathrm{yr}^{-1}$. If activity started at this level in 2020 we calculate that by $2050,19 \mathrm{PgC}(9 \mathrm{ppm})$ would be removed from the atmosphere, giving $\operatorname{RF}(2050) \approx-0.11 \mathrm{~W} \mathrm{~m}^{-2}$, and by 2100 , $40 \mathrm{PgC}(19 \mathrm{ppm})$ would be removed from the atmosphere giving $\mathrm{RF}(2100) \approx-0.20 \mathrm{~W} \mathrm{~m}^{-2}$. This is consistent with previous results (Aumount and Bopp, 2006) given our lower emissions scenario and the shorter interval of geoengineering - after 100 years of activity we estimate $\mathrm{RF} \approx-0.23 \mathrm{~W} \mathrm{~m}^{-2}$. An earlier estimate that atmospheric $\mathrm{CO}_{2}$ could be reduced by up to $15 \mathrm{ppm}$ from a baseline of $\sim 700 \mathrm{ppm}$ in 2100 (Zeebe and Archer, 2005), equates to a smaller $\mathrm{RF} \approx-0.11 \mathrm{~W} \mathrm{~m}^{-2}$. On the millennial timescale, literature estimates of the extra carbon that could be stored in the deep ocean from alleviating iron limitation range over 106-227 PgC (Aumount and Bopp, 2006). The upper value translates to $\mathrm{RF}_{\text {final }} \approx-0.29 \mathrm{~W} \mathrm{~m}^{-2}$ due to removing $41 \mathrm{PgC}(19 \mathrm{ppm})$ from the atmosphere in our strong mitigation scenario.

\subsubsection{Enhance upwelling}

For ocean pipes (Lovelock and Rapley, 2007) or pumps to work as a method of carbon sequestration they must avoid the problem that the water they bring up will be enriched in DIC as well as nutrients, and could potentially act as a net source of $\mathrm{CO}_{2}$ to the atmosphere (Shepherd et al., 2007). 
Possible solutions are to bring up water that is enriched in nitrogen relative to carbon (assuming $\mathrm{N}$ is the limiting nutrient) (Lampitt et al., 2008), or bring up water enriched in phosphorus relative to carbon and trigger nitrogen fixation (Karl and Letelier, 2008). Concentrating on the first option, it is well established that nitrogen is preferentially remineralised from sinking organic matter relative to carbon, and the natural upwelling of this water is what allows net export of carbon to the deep ocean (i.e. the biological pump) to occur. Taking station ALOHA near Hawaii (in the North Pacific subtropical gyre) as representative of ocean gyres, approximately $20 \%$ of upwelling nitrate (and corresponding carbon export) is converted to a sequestration flux of carbon. Thus, if the upwelling flux into surface ocean gyres which all had and maintained complete nitrate utilisation could be enhanced by $1 \mathrm{~Sv}$ globally, assuming an average $30.9 \mu \mathrm{mol} \mathrm{kg}^{-1}$ of nitrate in the upwelling water (which means pipes from $\sim 500 \mathrm{~m}$ depth), the global export flux could increase by $0.08 \mathrm{PgC} \mathrm{yr}^{-1}$ (i.e. about $0.7 \%$ ), but the corresponding sequestration flux would only be $\sim 0.016 \mathrm{PgC} \mathrm{yr}^{-1}$. To achieve $1 \mathrm{~Sv}$ of upwelling would require 4.32 million pumps of the capacity proposed by Atmocean Inc. (http://www.atmocean. $\mathrm{com} /$ sequestration.htm). Assuming activity started in 2020, by $20500.3 \mathrm{PgC}(0.1 \mathrm{ppm})$ could be removed from the atmosphere with a maximum $\operatorname{RF}(2050) \approx-0.0017 \mathrm{~W} \mathrm{~m}^{-2}$, whilst in $2100,0.6 \mathrm{PgC}(0.3 \mathrm{ppm})$ could be removed with a maximum $\mathrm{RF}(2100) \approx-0.0032 \mathrm{~W} \mathrm{~m}^{-2}$. Maintaining such activity to the end of the millennium gives $\mathrm{RF}_{\text {final }} \approx-0.028 \mathrm{~W} \mathrm{~m}^{-2}$, which in a strong mitigation scenario corresponds to removing $4.0 \mathrm{PgC}(1.9 \mathrm{ppm})$.

\subsubsection{Enhance downwelling}

A range of methods aimed at increasing the North Atlantic Deep Water (NADW) production by 1 Sverdrup (Sv, $10^{6} \mathrm{~m}^{3} \mathrm{~s}^{-1}$ ), from its current flow rate of 13-20 Sv, have been considered (Zhou and Flynn, 2005). This could be achieved by cooling surface waters by $1^{\circ} \mathrm{C}$, by having large floating pumps that form and thicken sea ice. The increase in downwelling current has been estimated to lead to a net annual incremental flux of $0.0095 \mathrm{PgC} \mathrm{yr}^{-1}$ (Zhou and Flynn, 2005). Assuming activity starts in 2020, and that storage is permanent, and allowing for atmospheric adjustment, in 2050 a total of $0.18 \mathrm{PgC}(0.08 \mathrm{ppm})$ would be removed from the atmosphere, giving a maximum $\mathrm{RF}(2050) \approx-0.00095 \mathrm{~W} \mathrm{~m}^{-2}$. If the activity continued to 2100 , a total of $0.38 \mathrm{PgC}$ $(0.18 \mathrm{ppm})$ would be removed from the atmosphere, giving $\mathrm{RF}(2100) \approx-0.0019 \mathrm{~W} \mathrm{~m}^{-2}$. Even if activity continued to 3000 , on a strong mitigation scenario only $2.4 \mathrm{PgC}$ $(1.1 \mathrm{ppm})$ would be removed from the atmosphere, giving $\mathrm{RF}_{\text {final }} \approx-0.016 \mathrm{~W} \mathrm{~m}^{-2}$. The actual value would be less as ocean storage is not permanent, and the method also has high costs (Zhou and Flynn, 2005).

\subsubsection{Carbonate addition to the ocean}

The alkalinity of the ocean could be increased by adding carbonate, thus increasing carbon uptake (Kheshgi, 1995). A detailed account has been presented based on using a flotilla of ships to sprinkle finely ground limestone $\left(\mathrm{CaCO}_{3}\right)$ on areas of the surface ocean where the depth of the saturation horizon is shallow $(250-500 \mathrm{~m})$ and the upwelling velocity is large (30-300 $\left.\mathrm{m} \mathrm{yr}^{-1}\right)$ (Harvey, 2008). A sink of $0.27 \mathrm{PgC} \mathrm{yr}^{-1}$ has been calculated after a century of linearly ramping up activity, and if maintained for a further $\sim 400$ years it could reduce atmospheric $\mathrm{CO}_{2}$ by $\sim 30 \mathrm{ppm}$ relative to a strong mitigation baseline of $450 \mathrm{ppm}$ (Harvey, 2008), giving $\mathrm{RF}(2500) \approx-0.36 \mathrm{~W} \mathrm{~m}^{-2}$. In our strong mitigation scenario we calculate a weaker effect on atmospheric $\mathrm{CO}_{2}$ of $36.2 \mathrm{PgC}(17 \mathrm{ppm})$ removed in 2500 giving $\mathrm{RF}(2500) \approx-0.20 \mathrm{~W} \mathrm{~m}^{-2}$. On the way there, in $20500.9 \mathrm{PgC}(0.4 \mathrm{ppm})$ are removed from the atmosphere and $\mathrm{RF}(2050) \approx-0.0048 \mathrm{~W} \mathrm{~m}^{-2}$, in $21004.9 \mathrm{PgC}$ $(2.3 \mathrm{ppm})$ are removed and $\mathrm{RF}(2100) \approx-0.025 \mathrm{~W} \mathrm{~m}^{-2}$. Assuming activity continued to 3000 , a total of $251 \mathrm{PgC}$ could be sequestered, removing $65 \mathrm{PgC}(30 \mathrm{ppm})$ from the atmosphere in our strong mitigation scenario, and giving $\mathrm{RF}_{\text {final }} \approx-0.46 \mathrm{~W} \mathrm{~m}^{-2}$.

\section{Discussion}

Our results (Tables 1 and 2) are only as good as the input data and the assumptions that go into the calculations. Taking them at face value for now, we can compare the maximum radiative forcing potential of quite different climate geoengineering options, summarized graphically in Fig. 2. The geoengineering results can be contrasted with the radiative forcing due to anthropogenic $\mathrm{CO}_{2}$ emissions, which even in a strong mitigation scenario will remain $>1 \mathrm{~W} \mathrm{~m}^{-2}$ for the rest of the millennium, exceeding $3 \mathrm{~W} \mathrm{~m}^{-2}$ on the century timescale. Without mitigation, anthropogenic $\mathrm{CO}_{2}$ forcing could reach $\sim 7 \mathrm{~W} \mathrm{~m}^{-2}$ on the century timescale and remain $>7 \mathrm{~W} \mathrm{~m}^{-2}$ on the millennial timescale. If we take 2100 as a time horizon for comparison and assume that the different shortwave geoengineering options could all be deployed on this timescale, then the various options cluster into groups in terms of their potential to counteract the radiative forcing from mitigated $\mathrm{CO}_{2}$ levels (Fig. 2).

Relatively few geoengineering options have the potential to counteract $>3 \mathrm{~W} \mathrm{~m}^{-2}$ alone. Placing sunshades in space or increasing planetary albedo by injecting stratospheric aerosols appear to be the only options that can achieve a reasonably uniform $-3 \mathrm{~W} \mathrm{~m}^{-2}$ and be scaled up if necessary. Increasing marine stratiform cloud albedo can probably achieve $-3 \mathrm{~W} \mathrm{~m}^{-2}$ of globally averaged radiative forcing but the effects are necessarily more regional and patchy, so less good regional cancellation of longwave radiative forcing is to be expected. These measures all have relatively short lifetimes so need to be continually replenished to maintain their effects. 


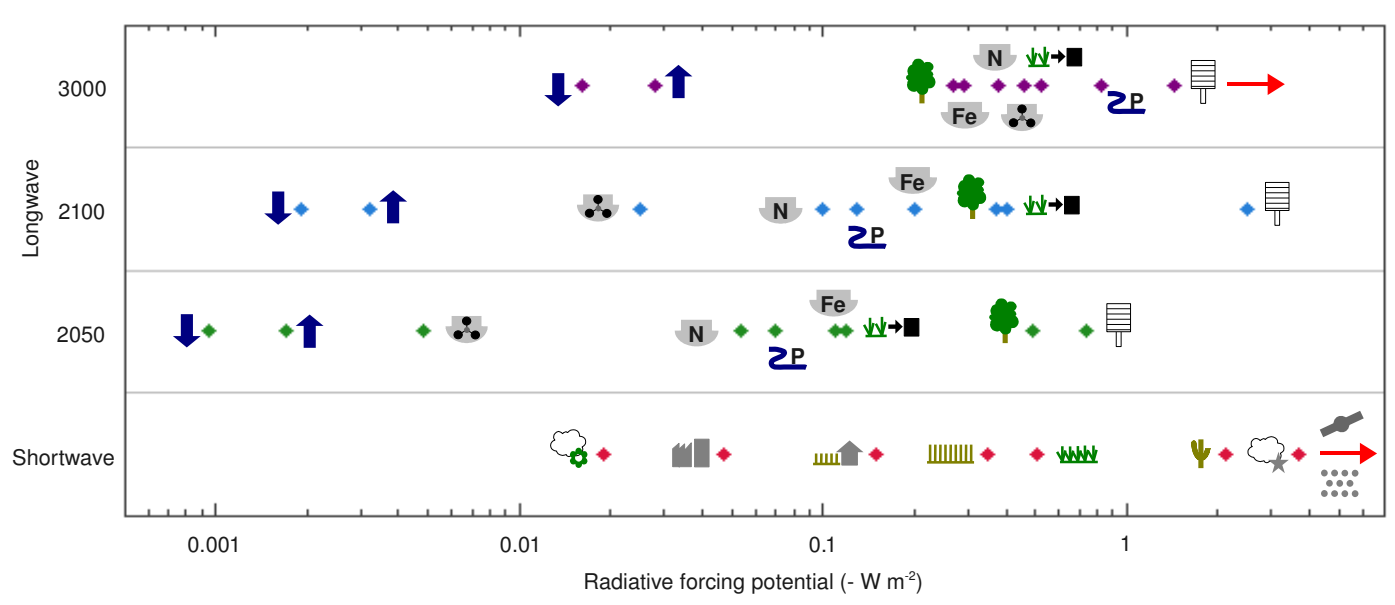

\begin{tabular}{|c|c|c|c|c|}
\hline Longwave Options & N Nitrogen fertilisation & Shortwave Options & $\psi$ & Desert \\
\hline Afforestation & Fe Iron fertilisation & Mirrors in space & waw & Grassland \\
\hline$\underline{v} \rightarrow \mathbf{D}$ Bio-char production & Enhance upwelling & $\because \because$ Stratosperhic aerosols & 피피 & Cropland \\
\hline 貫 Air capture and storage & Enhance downwelling & Cloud albedo - mechanical & 핑 & Human settlement \\
\hline 2P Phosphorus fertilisation & $\therefore$ Carbonate addition & Cloud albedo - biological & $M$ & Urban areas \\
\hline
\end{tabular}

Fig. 2. Summary of our estimates of the radiative forcing potential of different climate geoengineering options (from Tables 1 and 2 and Sects. 3.1.1 and 3.1.2). Note the logarithmic scale for (negative) radiative forcing potential. The potential of longwave $\left(\mathrm{CO}_{2}\right.$ removal) options is given on three different time horizons, assuming our baseline strong mitigation scenario. The rightward pointing arrows, which refer to mirrors in space, stratospheric aerosols, and air capture and storage on the year 3000 timescale, indicate that their potential could be greater than suggested by the diamonds (which in these cases represent a target radiative forcing to be counteracted: $3.71 \mathrm{~W} \mathrm{~m}{ }^{-2}$ due to $2 \times \mathrm{CO}_{2}=556 \mathrm{ppm}$ for the shortwave options, and $1.43 \mathrm{~W} \mathrm{~m}^{-2}$ due to $363 \mathrm{ppm} \mathrm{CO}_{2}$ in the year 3000 under our strong mitigation scenario).

A couple of other measures could cancel $>1 \mathrm{~W} \mathrm{~m}^{-2}$ alone. Air capture of $\mathrm{CO}_{2}$, either by plants as bio-energy or by chemical means, followed by carbon storage could achieve $\sim-2.5 \mathrm{~W} \mathrm{~m}^{-2}$ on the century timescale and has the advantage of acting globally. Greatly increasing the albedo of desert regions might achieve $>-2 \mathrm{~W} \mathrm{~m}^{-2}$ but would be biased to those regions, and the albedo change (and hence the radiative forcing) achievable may have been significantly over-estimated.

If the estimates for the aforementioned options are seriously in error, or they were deemed unacceptable for other reasons, then a number of other options have potential magnitude $0.1-1 \mathrm{~W} \mathrm{~m}^{-2}$. However, a combination of these would be required to counteract foreseeable anthropogenic radiative forcing, reminiscent of how the mitigation challenge has been broken down into a series of carbon "wedges" (Pacala and Socolow, 2004). Increasing the albedo of all grasslands, croplands and human settlements together could achieve $\sim-1.0 \mathrm{~W} \mathrm{~m}^{-2}$, but this may be an overestimate if there is overlap between what is classed as cropland and what is classed as human settlement. Afforestation combined with bio-char production could give $\sim-0.8 \mathrm{~W} \mathrm{~m}^{-2}$. Combined global iron, nitrogen and phosphorus fertilisation of the ocean might achieve $\sim-0.4 \mathrm{~W} \mathrm{~m}^{-2}$. If we could add up all these potential contributions (which is probably not valid), they would give a radiative forcing of $\sim-2.2 \mathrm{~W} \mathrm{~m}^{-2}$, not enough to cancel the contribution of even strongly mitigated $\mathrm{CO}_{2}$ emissions (and it would not be globally uniform).

Increasing ocean alkalinity, biologically enhancing cloud albedo in the Southern Ocean summer, or increasing the albedo of urban areas, could each only cancel $\sim 1 \%$ of the anticipated forcing on the century timescale, even under strong mitigation of $\mathrm{CO}_{2}$ emissions (i.e. $\sim 0.03 \mathrm{~W} \mathrm{~m}^{-2}$ ). Enhancing ocean upwelling or downwelling have an order of magnitude weaker effect still.

On the nearer time horizon of 2050, a minimum atmospheric $\mathrm{CO}_{2}$ of $450 \mathrm{ppm}$ in the absence of geoengineering would give $\sim 2.6 \mathrm{~W} \mathrm{~m}^{-2}$ radiative forcing, and combining all the upper estimates for carbon cycle geoengineering options (Table 2) gives $\sim-1.6 \mathrm{~W} \mathrm{~m}^{-2}$. Thus, it would appear that only rapid, repeated, large-scale deployment of potent shortwave geoengineering options (e.g. stratospheric aerosols) could conceivably cool the climate to near its preindustrial state on the 2050 timescale. However, some carbon cycle geoengineering options could make a useful contribution of similar magnitude to identified mitigation "wedges" (Pacala and Socolow, 2004). In the most optimistic scenarios, air capture and storage by BECS, combined with afforestation and bio-char production appears to have the potential to remove $\sim 100 \mathrm{ppm}$ of $\mathrm{CO}_{2}$ from the atmosphere 
giving $-1.35 \mathrm{~W} \mathrm{~m}^{-2}$. Combined iron, nitrogen and phosphorus fertilisation of the ocean can only achieve a maximum $\sim 20 \mathrm{ppm} \mathrm{CO}_{2}$ drawdown and $-0.23 \mathrm{~W} \mathrm{~m}^{-2}$ on the 2050 timescale.

On the millennial timescale, the most potent options (sunshades, stratospheric aerosols, mechanically increasing marine cloud albedo, increasing desert albedo, and air capture and storage of $\mathrm{CO}_{2}$ ) remain so. However, the ranking of the remaining geoengineering options changes significantly (Fig. 2). After air capture and storage of liquid $\mathrm{CO}_{2}$ (in sediments or geologic reservoirs), phosphorus addition to the ocean appears to offer the next largest long-term potential carbon store, and it is unique in that it will probably continue to happen inadvertently. Bio-char in soil offers the greatest potential for long-term carbon storage on land. These two options combined may have the potential to store nearly all the cumulative carbon emissions from a strong mitigation scenario $(1000 \mathrm{PgC})$. Increasing ocean alkalinity goes from being ineffective on the century timescale to having a potentially significant role to play in climate cooling on the millennial timescale, as well as having a potentially valuable role to play in combating ocean acidification (Harvey, 2008). Nitrogen and iron fertilisation of the ocean may have greater long term potential for carbon storage than afforestation on land but they require centuries of sustained activity to achieve it (whereas the potential of afforestation and reforestation could be realised within this century).

Enhancing ocean upwelling or downwelling can be eliminated as global cooling options on any of the timescales we consider, unless either could greatly exceed the $1 \mathrm{~Sv}$ we have assumed. Biologically enhancing cloud albedo in the Southern Ocean summer can be eliminated as a global cooling option, but might be effective as a regional seasonal cooling option to protect Antarctic ice shelves (Wingenter et al., 2007). Urban albedo alteration can also be eliminated as a global cooling option, but it can play a potentially important role in reducing urban heat islands and improving air quality (Taha, 2008).

Some interesting comparisons between shortwave and longwave options in a given realm (land or ocean) emerge. Globally altering the albedo of all grasslands and croplands together may have a slightly greater cooling potential $\left(\sim-0.9 \mathrm{~W} \mathrm{~m}^{-2}\right)$ than the combination of afforestation/reforestation and adding bio-char to soil $(\sim-0.6$ to $-0.8 \mathrm{~W} \mathrm{~m}^{-2}$, depending on the timescale). Mechanically enhancing marine stratiform cloud albedo appears to have a greater cooling potential than all ocean nutrient fertilisation measures combined. However, the longwave $\left(\mathrm{CO}_{2}\right)$ options act globally on the radiation balance whilst the shortwave options are regionally biased. Iron fertilisation of the Southern Ocean has $\sim-0.2 \mathrm{~W} \mathrm{~m}^{-2}$ global cooling potential via carbon uptake, but might generate up to $\sim-2 \mathrm{~W} \mathrm{~m}^{-2}$ regional cooling in summer via its effect on DMS emissions and cloud albedo (Wingenter et al., 2007).
On the face of it some encouraging results emerge from our analysis, but they come with very large caveats. We have examined maximum effects, which entail truly global deployment and may not be physically achievable (as upper limit values have generally been assumed). Deployment itself costs energy, which if obtained from fossil fuels would tend to counteract any reductions in radiative forcing achieved. For some options, e.g. adding calcium carbonate to the ocean, the $\mathrm{CO}_{2}$ emissions of deployment could be of the same order as the $\mathrm{CO}_{2}$ sink generated (Harvey, 2008). Generating the energy and materials required for global scale geoengineering in turn costs money, and we have ignored economic constraints.

If combined with strong mitigation, air capture of $\mathrm{CO}_{2}$ by plants providing bio-energy, followed by carbon storage, might be able to return atmospheric $\mathrm{CO}_{2}$ to pre-industrial levels sometime next century, thus removing the need for shortwave geoengineering to cool the climate beyond that time. Others have even argued that combining all land carbon cycle geoengineering options, atmospheric $\mathrm{CO}_{2}$ could be brought back to the pre-industrial level within this century (Read and Parshotam, 2007; Read, 2008). However, if one examines the land areas involved in such scenarios (which we have adopted), they appear to be in conflict with food production and/or the preservation of natural ecosystems. Furthermore, arguments that such scenarios would generate revenue (Read and Parshotam, 2007; Read, 2008) appear questionable (Keith et al., 2006). In a model that includes the estimated costs of different technologies, which assumes air capture is implemented over 50 years, it makes little impression until late this century with a sink of $\sim 2 \mathrm{PgC} \mathrm{yr}^{-1}$ generated by 2100 (Keith et al., 2006), much smaller than we have assumed in the above calculations. Thus, we are sceptical about the feasibility or desirability of the BECS option, as currently framed. Concerns about land-use conflicts are largely eliminated by the chemical air capture and storage option, but its estimated costs are considerably higher (Keith et al., 2006). Putting economic concerns aside, the main feasibility constraint is the size and accessibility of geologic reservoirs for storing the captured $\mathrm{CO}_{2}$.

Continual addition of phosphorus, nitrogen, iron and calcium carbonate to the ocean, if it could eliminate nitrogen and iron limitation and allow global export production to track increasing phosphorus input, could, when combined with strong mitigation, bring atmospheric $\mathrm{CO}_{2}$ back to the pre-industrial level by the end of the millennium. However, this is a mammoth geoengineering task which would itself severely disrupt marine ecosystems, and we doubt whether the elimination of nitrogen limitation could be achieved. If these methods started to be successful and carbon export to depth increased significantly, it would generate widespread ocean anoxia as there would be no corresponding increase in oxygen supply. This in turn would be expected to trigger increased denitrification, removing nitrogen from the ocean and thus providing a strong negative feedback on increasing 
export production (Lenton and Watson, 2000). Phosphorus addition generates a carbon sink in coastal seas where carbon is sequestered in sediments (rather than deep water), but this also entails eutrophication and potentially toxic algal blooms.

Land surface albedo modification methods appear to have a combined global potential of $\sim-3 \mathrm{~W} \mathrm{~m}^{-2}$ (Table 1), but are best considered as regional climate cooling options, because the actual forcing over the relevant regions would be much greater than this, which could lead to excessive regional cooling. The effectiveness of albedo modification methods depends greatly on the magnitude of albedo enhancement achievable and the area it is applied to, and we question some of the values proposed. Increasing the albedo of deserts by 0.44 essentially involves covering them up with a highly reflective material, but this would surely itself get covered in matter deposited from the atmosphere, reducing its albedo or demanding regular cleaning and replacement. The assumption of 3.25 million $\mathrm{km}^{2}$ of human settlement (Hamwey, 2007) appears questionable, given that some estimates put the coverage of urban areas at less than a tenth of this (Hansen et al., 2000; Loveland et al., 2000). If realistic it must include many land surface types, probably dominated by pastures, for which an increase of albedo of 0.15 seems questionable given that a value of 0.04 is suggested for grasslands and croplands (Hamwey, 2007).

Turning to the ocean and proposals to mechanically enhance the albedo of marine stratiform clouds, all papers thus far (Latham, 2002; Bower et al., 2006; Latham et al., 2008) appear to have been based on under-estimates of the albedo change required to provide a given radiative forcing. Thus, revised calculations are required of the source flux of $\mathrm{CCN}$ required in different regions to give the necessary top-ofcloud albedo change, given the known saturating response of cloud albedo to adding CCN (Twomey, 1991). The atmosphere over the Southern Ocean is the most pristine in this respect and should exhibit the strongest response, yet recent reassessments of the biological approach to seasonally enhancing cloud albedo in this region (Woodhouse et al., 2008) suggest it may be a lot harder to achieve a given effect than originally assumed (Wingenter et al., 2007).

There are many other issues and caveats that should be considered in evaluating the various geoengineering proposals. In a separate paper (Vaughan and Lenton, 2009) we consider the side effects on other aspects of the Earth system, the timescales to develop and deploy different technologies, their reversibility and the rate at which their effects decay. For a good example of calculations of the cost and $\mathrm{CO}_{2}$ emissions associated with deploying a specific option see (Harvey, 2008).

\section{Conclusions}

Climate geoengineering is best considered as a potential complement to the mitigation of $\mathrm{CO}_{2}$ emissions, rather than as an alternative to it. Strong mitigation could achieve the equivalent of up to $-4 \mathrm{~W} \mathrm{~m}^{-2}$ radiative forcing on the century timescale, relative to a worst case scenario for rising $\mathrm{CO}_{2}$. However, to tackle the remaining $3 \mathrm{~W} \mathrm{~m}^{-2}$, which are likely even in a best case scenario of strongly mitigated $\mathrm{CO}_{2}$, a number of geoengineering options show promise. Some shortwave geoengineering measures, most promisingly stratospheric aerosol injections, have the potential to roughly cancel mitigated $\mathrm{CO}_{2}$ radiative forcing. Alternatively, a combination of land surface albedo modifications and mechanical enhancement of marine stratiform cloud albedo, could achieve a patchy or partial cancellation of mitigated $\mathrm{CO}_{2}$ radiative forcing. However, most shortwave options carry a heavy burden of risk because they have to be continually replenished and if deployment is suddenly stopped, extremely rapid warming could ensue. Carbon cycle geoengineering carries less risk associated with failure and some options appear to have the unique potential to return $\mathrm{CO}_{2}$ to its pre-industrial level within a couple of centuries, which will not happen naturally, even on a millennial timescale. Air capture and storage shows the greatest potential, combined with afforestation, reforestation and bio-char production. If our estimates are even remotely accurate, recent interest in ocean carbon cycle geoengineering seems a little misplaced, because even the more promising options are only worth considering as a millennial timescale activity. Perhaps the most surprising result is that activities that are already underway, particularly inadvertent phosphorus addition to coastal and shelf seas, may have greater long-term carbon sequestration potential than the much-studied iron fertilisation. Some other suggestions that have received considerable media attention, in particular "ocean pipes" appear to be ineffective. The real value of such suggestions has been to redirect attention to the whole topic area. We hope that the present contribution provides a useful quantitative first step that can inform the prioritisation of further research into various climate geoengineering options, and provide a common framework for the evaluation of new proposals. 


\section{Appendix A}

\section{Solutions for $\mathrm{CO}_{2}$ removed from the atmosphere}

Letting $\Delta t=t_{f}-t$ and inserting Eqs. (15) and (16) into (17) gives:

$$
\begin{aligned}
& \Delta C_{\mathrm{atm}}=-\int_{t_{s}}^{t_{c}} R(t) s\left(t_{f}-t\right) f\left(t_{f}-t\right) d t \\
& =-\int_{t_{s}}^{t_{c}} R(t)\left(\begin{array}{l}
0.18 e^{\frac{\left(t-t_{f}\right)}{\tau}}+0.14 e^{\left(t-t_{f}\right)\left(\frac{1}{\tau}+\frac{1}{420}\right)}+0.18 e^{\left(t-t_{f}\right)\left(\frac{1}{\tau}+\frac{1}{70}\right)} \\
+0.24 e^{\left(t-t_{f}\right)\left(\frac{1}{\tau}+\frac{1}{21}\right)}+0.26 e^{\left(t-t_{f}\right)\left(\frac{1}{\tau}+\frac{1}{3.4}\right)}
\end{array}\right) d t
\end{aligned}
$$

Alternatively, assuming permanent sequestration, $s\left(t_{f}-t\right)=1$ :

$$
\begin{aligned}
& \Delta C_{\mathrm{atm}}=-\int_{t_{s}}^{t_{c}} R(t) f\left(t_{f}-t\right) d t \\
& =-\int_{t_{s}}^{t_{c}} R(t)\left(0.18+0.14 e^{\left(t-t_{f}\right) / 420}+0.18 e^{\left(t-t_{f}\right) / 70}+0.24 e^{\left(t-t_{f}\right) / 21}+0.26 e^{\left(t-t_{f}\right) / 3.4}\right) d t
\end{aligned}
$$

The presentation is simplified if we define the start time of geoengineering action, $t_{s}=0$. We then consider 3 cases for the geoengineering carbon removal function, $R(t)$ :

(a) Constant removal $R(t)=a$ (in $\mathrm{PgC} \mathrm{yr}^{-1}$ ) is the simplest case:

$$
\begin{aligned}
& \Delta C_{\mathrm{atm}}=-\int_{0}^{t_{c}} R(t) s\left(t_{f}-t\right) f\left(t_{f}-t\right) d t=-a \int_{0}^{t_{c}} s\left(t_{f}-t\right) f\left(t_{f}-t\right) d t \\
& =-a\left(\begin{array}{l}
0.18 \tau\left(e^{\frac{\left(t_{c}-t_{f}\right)}{\tau}}-e^{-\frac{t_{f}}{\tau}}\right)+\frac{0.14}{\left(\frac{1}{\tau}+\frac{1}{420}\right)}\left(e^{\left(t_{c}-t_{f}\right)\left(\frac{1}{\tau}+\frac{1}{420}\right)}-e^{-t_{f}\left(\frac{1}{\tau}+\frac{1}{420}\right)}\right) \\
+\frac{0.18}{\left(\frac{1}{\tau}+\frac{1}{70}\right)}\left(e^{\left(t_{c}-t_{f}\right)\left(\frac{1}{\tau}+\frac{1}{70}\right)}-e^{-t_{f}\left(\frac{1}{\tau}+\frac{1}{70}\right)}\right)+\frac{0.24}{\left(\frac{1}{\tau}+\frac{1}{21}\right)}\left(e^{\left(t_{c}-t_{f}\right)\left(\frac{1}{\tau}+\frac{1}{21}\right)}-e^{-t_{f}\left(\frac{1}{\tau}+\frac{1}{21}\right)}\right) \\
+\frac{0.26}{\left(\frac{1}{\tau}+\frac{1}{3.4}\right)}\left(e^{\left(t_{c}-t_{f}\right)\left(\frac{1}{\tau}+\frac{1}{3.4}\right)}-e^{-t_{f}\left(\frac{1}{\tau}+\frac{1}{3.4}\right)}\right)
\end{array}\right)
\end{aligned}
$$

In the case of permanent sequestration, $s\left(t_{f}-t\right)=1$ :

$$
\begin{aligned}
& \Delta C_{\mathrm{atm}}=-a \int_{0}^{t_{c}} f\left(t_{f}-t\right) d t \\
& =-a\left(\begin{array}{l}
0.18 t_{c}+58.8\left(e^{\frac{\left(t_{c}-t_{f}\right)}{420}}-e^{-\frac{t_{f}}{420}}\right)+12.6\left(e^{\frac{\left(t_{c}-t_{f}\right)}{70}}-e^{-\frac{t_{f}}{70}}\right) \\
+5.04\left(e^{\frac{\left(t_{c}-t_{f}\right)}{21}}-e^{-\frac{t_{f}}{21}}\right)+0.884\left(e^{\frac{\left(t_{c}-t_{f}\right)}{3.4}}-e^{-\frac{t_{f}}{3.4}}\right)
\end{array}\right)
\end{aligned}
$$

(b) Linearly increasing removal with time $R(t)=b t$, where $b\left(\right.$ in $\left.\mathrm{PgC} \mathrm{yr}^{-2}\right)$ is the rate of increase in removal, requires integration by parts and gives:

$$
\begin{aligned}
& \Delta C_{\mathrm{atm}}=-\int_{0}^{t_{c}} R(t) s\left(t_{f}-t\right) f\left(t_{f}-t\right) d t=-b \int_{0}^{t_{c}} t s\left(t_{f}-t\right) f\left(t_{f}-t\right) d t \\
& =-b\left(\begin{array}{l}
0.18 \tau e^{\frac{\left(t_{c}-t_{f}\right)}{\tau}}\left(t_{c}-\tau\right)+0.18 \tau^{2} e^{-\frac{t_{f}}{\tau}}+\frac{0.14}{\left(\frac{1}{\tau}+\frac{1}{420}\right)} e^{\left(t_{c}-t_{f}\right)\left(\frac{1}{\tau}+\frac{1}{420}\right)}\left(t_{c}-\frac{1}{\left(\frac{1}{\tau}+\frac{1}{420}\right)}\right) \\
+\frac{0.14}{\left(\frac{1}{\tau}+\frac{1}{420}\right)^{2}} e^{-t_{f}\left(\frac{1}{\tau}+\frac{1}{420}\right)}+\frac{0.18}{\left(\frac{1}{\tau}+\frac{1}{70}\right)} e^{\left(t_{c}-t_{f}\right)\left(\frac{1}{\tau}+\frac{1}{70}\right)}\left(t_{c}-\frac{1}{\left(\frac{1}{\tau}+\frac{1}{70}\right)}\right) \\
+\frac{0.18}{\left(\frac{1}{\tau}+\frac{1}{70}\right)^{2}} e^{-t_{f}\left(\frac{1}{\tau}+\frac{1}{70}\right)}+\frac{0.24}{\left(\frac{1}{\tau}+\frac{1}{21}\right)} e^{\left(t_{c}-t_{f}\right)\left(\frac{1}{\tau}+\frac{1}{21}\right)}\left(t_{c}-\frac{1}{\left(\frac{1}{\tau}+\frac{1}{21}\right)}\right) \\
+\frac{0.24}{\left(\frac{1}{\tau}+\frac{1}{21}\right)^{2}} e^{-t_{f}\left(\frac{1}{\tau}+\frac{1}{21}\right)}+\frac{0.26}{\left(\frac{1}{\tau}+\frac{1}{3.4}\right)} e^{\left(t_{c}-t_{f}\right)\left(\frac{1}{\tau}+\frac{1}{3.4}\right)}\left(t_{c}-\frac{1}{\left(\frac{1}{\tau}+\frac{1}{3.4}\right)}\right) \\
+\frac{0.26}{\left(\frac{1}{\tau}+\frac{1}{3.4}\right)^{2}} e^{-t_{f}\left(\frac{1}{\tau}+\frac{1}{3.4}\right)}
\end{array}\right)
\end{aligned}
$$


In the case of permanent sequestration, $s\left(t_{f}-t\right)=1$ :

$$
\begin{aligned}
& \Delta C_{\mathrm{atm}}=-b \int_{0}^{t_{c}} t f\left(t_{f}-t\right) d t \\
& =-b\left(\begin{array}{l}
0.09 t_{c}^{2}+58.8 t_{c} e^{\frac{\left(t_{c}-t_{f}\right)}{420}}+24696\left(e^{-\frac{t_{f}}{420}}-e^{\frac{\left(t_{c}-t_{f}\right)}{420}}\right)+12.6 t_{c} e^{\frac{\left(t_{c}-t_{f}\right)}{70}} \\
+882\left(e^{-\frac{t_{f}}{70}}-e^{\frac{\left(t_{c}-t_{f}\right)}{70}}\right)+5.04 t_{c} e^{\frac{\left(t_{c}-t_{f}\right)}{21}}+105.84\left(e^{-\frac{t_{f}}{21}}-e^{\frac{\left(t_{c}-t_{f}\right)}{21}}\right) \\
+0.884 t_{c} e^{\frac{\left(t_{c}-t_{f}\right)}{3.4}}+3.0056\left(e^{-\frac{t_{f}}{3.4}}-e^{\frac{\left(t_{c}-t_{f}\right)}{3.4}}\right)
\end{array}\right)
\end{aligned}
$$

(c) Exponentially increasing removal with time, $R(t)=R_{0} e^{c t}$, where $R_{0}\left(\right.$ in $\left.\mathrm{PgC} \mathrm{yr}^{-1}\right)$ is the initial removal rate and $c\left(\mathrm{yr}^{-1}\right)$ is the fractional rate of increase in geoengineering activity, gives:

$$
\begin{aligned}
& \Delta C_{\mathrm{atm}}=-\int_{0}^{t_{c}} R(t) s\left(t_{f}-t\right) f\left(t_{f}-t\right) d t=-R_{0} \int_{0}^{t_{c}} e^{c t} s\left(t_{f}-t\right) f\left(t_{f}-t\right) d t \\
& =-R_{0}\left(\begin{array}{l}
\frac{0.18}{\left(c+\frac{1}{\tau}\right)}\left(e^{\left(c+\frac{1}{\tau}\right) t_{c}-\frac{t_{f}}{\tau}}-e^{-\frac{t_{f}}{\tau}}\right)+\frac{0.14}{\left(c+\frac{1}{\tau}+\frac{1}{420}\right)}\left(e^{\left(c+\frac{1}{\tau}+\frac{1}{420}\right) t_{c}-\left(\frac{1}{\tau}+\frac{1}{420}\right) t_{f}}-e^{-\left(\frac{1}{\tau}+\frac{1}{420}\right) t_{f}}\right) \\
+\frac{0.18}{\left(c+\frac{1}{\tau}+\frac{1}{70}\right)}\left(e^{\left(c+\frac{1}{\tau}+\frac{1}{70}\right) t_{c}-\left(\frac{1}{\tau}+\frac{1}{70}\right) t_{f}}-e^{-\left(\frac{1}{\tau}+\frac{1}{70}\right) t_{f}}\right) \\
+\frac{0.24}{\left(c+\frac{1}{\tau}+\frac{1}{21}\right)}\left(e^{\left(c+\frac{1}{\tau}+\frac{1}{21}\right) t_{c}-\left(\frac{1}{\tau}+\frac{1}{21}\right) t_{f}}-e^{-\left(\frac{1}{\tau}+\frac{1}{21}\right) t_{f}}\right) \\
+\frac{0.26}{\left(c+\frac{1}{\tau}+\frac{1}{3.4}\right)}\left(e^{\left(c+\frac{1}{\tau}+\frac{1}{3.4}\right) t_{c}-\left(\frac{1}{\tau}+\frac{1}{3.4}\right) t_{f}}-e^{-\left(\frac{1}{\tau}+\frac{1}{3.4}\right) t_{f}}\right)
\end{array}\right)
\end{aligned}
$$

In the case of permanent sequestration, $s\left(t_{f}-t\right)=1$ :

$$
\begin{aligned}
& \Delta C_{\mathrm{atm}}=-R_{0} \int_{0}^{t_{c}} e^{c t} f\left(t_{f}-t\right) d t \\
& =-R_{0}\left(\begin{array}{l}
\frac{0.18}{c}\left(e^{c t_{c}}-1\right)+\frac{0.14}{\left(c+\frac{1}{420}\right)}\left(e^{c t_{c}+\frac{\left(t_{c}-t_{f}\right)}{420}}-e^{-\frac{t_{f}}{420}}\right)+\frac{0.18}{\left(c+\frac{1}{70}\right)}\left(e^{c t_{c}+\frac{\left(t_{c}-t_{f}\right)}{70}}-e^{-\frac{t_{f}}{70}}\right) \\
+\frac{0.24}{\left(c+\frac{1}{21}\right)}\left(e^{c t_{c}+\frac{\left(t_{c}-t_{f}\right)}{21}}-e^{-\frac{t_{f}}{21}}\right)+\frac{0.26}{\left(c+\frac{1}{3.4}\right)}\left(e^{c t_{c}+\frac{\left(t_{c}-t_{f}\right)}{3.4}}-e^{-\frac{t_{f}}{3.4}}\right)
\end{array}\right)
\end{aligned}
$$

These solutions can readily be combined for removal scenarios that have different phases using different removal functions drawn from cases (a)-(c).

Acknowledgements. We thank J. Lovelock for inspiring TML to think about the topic, A. Watson, P. Williamson and P. Goodwin for comments on earlier drafts, and two anonymous referees for their constructive critiques. We thank the organisers and participants of the 38th Session of the International Seminar on Nuclear War and Planetary Emergencies in Erice, Italy, August 2007 and of the Workshop on Earth System Engineering in Wilbad Kreuth, Germany, September 2008 for stimulating discussions on climate geoengineering. TML's contribution is part of the "Feedbacks QUEST" project of the Natural Environment Research Council (NE/F001657/1). NEV is a Tyndall PhD student funded by the School of Environmental Sciences.

Edited by: W. T. Sturges

\section{References}

Ackerman, A. S., Kirkpatrick, M. P., Stevens, D. E., and Toon, O. B.: The impact of humidity above stratiform clouds on indirect aerosol climate forcing, Nature, 432, 1014-1017, 2004.

Akbari, H., Menson, S., and Rosenfeld, A.: Global Cooling: Increasing world-wide urban albedos to offset $\mathrm{CO}_{2}$, Climatic
Change, 94, 275-286, 2009.

Albrecht, B. A.: Aerosols, cloud microphysics, and fractional cloudiness, Science, 245, 1227-1230, 1989.

Anderson, L. A. and Sarmiento, J. L.: Redfield ratios of remineralization determined by nutrient data analysis, Global Biogeochem. Cy., 8, 65-80, 1994.

Angel, R.: Feasibility of cooling the earth with a cloud of small spacecraft near the inner Lagrange point (11), P. Natl. Acad. Sci. USA, 103, 17184-17189, 2006.

Aumount, O. and Bopp, L.: Globalizing results from ocean in situ iron fertilization studies, Global Biogeochem. Cy., 20, GB2017, doi:10.1029/2005GB002591, 2006.

Betts, R. A., Falloon, P. D., Goldewijk, K. K., and Ramankutty, N.: Biogeophysical effects of land use on climate: Model simulations of radiative forcing and large-scale temperature change, Agr. Forest Meteorol., 142, 216-233, 2007.

Bower, K., Choularton, T., Latham, J., Sahraei, J., and Salter, S.: Computational assessment of a proposed technique for global warming mitigation via albedo enhancement of marine stratocumulus clouds, Atmos. Res., 82, 328-336, 2006.

Boyd, P. W.: Ranking geo-engineering schemes, Nat. Geosci., 1, 722-724, 2008. 
Briegleb, B. P., Minnis, P., Ramanathan, V., and Harrison, E.: Comparison of regional clear-sky albedos inferred from satellite observations and model computations, J. Clim. Appl. Meteorol., 25, 214-226, 1986.

Brion, N., Baeyens, W., De Galan, S., Elskens, M., and Laane, R. W. P. M.: The North Sea: source or sink for nitrogen and phosphorus to the Atlantic Ocean?, Biogeochemistry, 68, 277-296, 2004.

Buesseler, K. O., Lamborg, C. H., Boyd, P. W., Lam, P. J., Trull, T. W., Bidigare, R. R., Bishop, J. K. B., Casciotti, K. L., Dehairs, F., Elskens, M., Honda, M., Karl, D. M., Siegel, D. A., Silver, M. W., Steinberg, D. K., Valdes, J., Van Mooy, B., and Wilson, S.: Revisiting Carbon Flux Through the Ocean's Twilight Zone, Science, 316, 567-570, 2007.

Caldeira, K. and Wood, L.: Global and Arctic climate engineering: numerical model studies, Philosop. T. R. Soc. A, 366, 40394056, 2008.

Canadell, J. G., LeQuere, C., Raupach, M. R., Field, C. B., Buitenhuis, E. T., Ciais, P., Conway, T. J., Gillett, N. P., Houghton, R. A., and Marland, G.: Contributions to accelerating atmospheric $\mathrm{CO}_{2}$ growth from economic activity, carbon intensity, and efficiency of natural sinks, P. Natl. Acad. Sci. USA, 104, 1886618870, 2007.

Charlson, R. J., Lovelock, J. E., Andreae, M. O., and Warren, S. G.: Oceanic phytoplankton, atmospheric sulphur, cloud albedo and climate, Nature, 326, 655-661, 1987.

Chen, T. S. and Ohring, G.: On the relationship between clear-sky planetary and surface albedos, J. Atmos. Sci., 41, 156-158, 1984.

Cox, P. M., Betts, R. A., Jones, C. D., Spall, S. A., and Totterdell, I. J.: Acceleration of global warming due to carbon-cycle feedbacks in a coupled climate model, Nature, 408, 184-187, 2000.

Crutzen, P. J.: Albedo enhancement by stratospheric sulphur injections: A contribution to resolve a policy dilemma?, Climatic Change, 77, 211-219, 2006.

Fairall, C. W., Hare, J. E., and Snider, J. B.: An eight-month sample of marine stratocumulus cloud fraction, albedo, and integrated liquid water, J. Climate, 3, 847-864, 1990.

Falkowski, P. G.: Evolution of the nitrogen cycle and its influence on the biological sequestration of $\mathrm{CO}_{2}$ in the ocean, Nature, 387, 272-275, 1997.

Feingold, G., Eberhard, W. L., Veron, D. A., and Previdi, M.: First measurements of the Twomey indirect effect using ground-based remote sensors, Geophys. Res. Lett., 30, 1287, doi:10.1029/2002GL016633, 2003.

Friedlingstein, P., Cox, P., Betts, R., Bopp, L., Bloh, W. v., Brovkin, V., Doney, S., Eby, M., Fung, I., Govindasamy, B., John, J., Jones, C., Joos, F., Kato, T., Kawamiya, M., Knorr, W., Lindsay, K., Matthews, H. D., Raddatz, T., Rayner, P., Reick, C., Roeckner, E., Schnitzler, K.-G., Schnur, R., Strassmann, K., Thompson, S., Weaver, A. J., Yoshikawa, C., and Zeng, N.: Climatecarbon cycle feedback analysis: Results from the C4MIP model intercomparison, J. Climate, 19, 3337-3353, 2006.

Gaskill, A.: Summary of Meeting with US DOE to discuss Geoengineering options to prevent abrupt and long-term climate change,

http://www.global-warming-geo-engineering.org/

DOE-Meeting/DOE-Geoengineering-Climate-Change-Meeting/ ag1.html, access: 9 July 2009, 2004.

Gehlen, M., Bopp, L., Emprin, N., Aumont, O., Heinze, C., and
Ragueneau, O.: Reconciling surface ocean productivity, export fluxes and sediment composition in a global biogeochemical ocean model, Biogeosciences, 3, 521-537, 2006, http://www.biogeosciences.net/3/521/2006/.

Govindasamy, B. and Caldeira, K.: Geoengineering Earth's radiation balance to mitigate $\mathrm{CO}_{2}$-induced climate change, Geophys. Res. Lett., 27, 2141-2144, 2000.

Hamwey, R. M.: Active amplification of the terrestrial albedo to mitigate climate change: An exploratory study, Mitigation and Adaptation Strategies for Global Change, 12, 419-439, 2007.

Hansen, J., Sato, M., Ruedy, R., Nazarenko, L., Lacis, A., Schmidt, G. A., Russell, G., Aleinov, I., Bauer, M., Bauer, S., Bell, N., Cairns, B., Canuto, V., Chandler, M., Cheng, Y., Del Genio, A., Faluvegi, G., Fleming, E., Friend, A., Hall, T., Jackman, C., Kelley, M., Kiang, N., Koch, D., Lean, J., Lerner, J., Lo, K., Menon, S., Miller, R., Minnis, P., Novakov, T., Oinas, V., Perlwitz, J., Perlwitz, J., Rind, D., Romanou, A., Shindell, D., Stone, P., Sun, S., Tausnev, N., Thresher, D., Wielicki, B., Wong, T., Yao, M., and Zhang, S.: Efficacy of climate forcings, J. Geophys. Res.Atmos., 110, D18104, doi:10.1029/2005JD005776, 2005.

Hansen, M. C., DeFries, R. S., Townshend, J. R. G., and Sohlberg, R.: Global land cover classification at $1 \mathrm{~km}$ spatial resolution using a classification tree approach, Int. J. Remote Sens., 21, 13311364, 2000.

Harvey, L. D. D.: Mitigating the atmospheric $\mathrm{CO}_{2}$ increase and ocean acidification by adding limestone powder to upwelling regions, J. Geophys. Res.-Oceans, 113, C04028, doi:10.1029/2007JC004373, 2008.

Houghton, R. A.: Carbon Flux to the Atmosphere from Land-Use Changes: 1850-2005, in: TRENDS: A Compendium of Data on Global Change, Carbon Dioxide Information Analysis Center, Oak Ridge National Laboratory, US Department of Energy, Oak Ridge, Tennesee, USA, 2008.

House, K. Z., Schrag, D. P., Harvey, C. F., and Lackner, K. S.: Permanent carbon dioxide storage in deep-sea sediments, P. Natl. Acad. Sci. USA, 103, 12291-12295, 2006.

IPCC: Climate Change 2001: The Scientific Basis, Cambridge University Press, Cambridge, 2001.

IPCC: Carbon Dioxide Capture and Storage, Cambridge University Press, Cambridge, 2005.

IPCC: Climate Change 2007: The Physical Science Basis, Cambridge University Press, Cambridge, 2007.

Jin, M., Dickinson, R. E., and Zhang, D.-L.: The Footprint of Urban Areas on Global Climate as Characterized by MODIS, J. Climate, 18, 1551-1565, 2005.

Jin, X., Gruber, N., Frenzel, H., Doney, S. C., and McWilliams, J. C.: The impact on atmospheric $\mathrm{CO}_{2}$ of iron fertilization induced changes in the ocean's biological pump, Biogeosciences, 5, 385406, 2008, http://www.biogeosciences.net/5/385/2008/.

Joos, F., Bruno, M., Fink, R., Siegenthaler, U., Stocker, T. F., LeQuere, C., and Sarmiento, J. L.: An efficient and accurate representation of complex oceanic and biospheric models of anthropogenic carbon uptake, Tellus, 48B, 397-417, 1996.

Karl, D. M. and Letelier, R.: Nitrogen fixation-enhanced carbon sequestration in low nitrate, low chlorophyll seascapes, Mar. Ecol.Prog. Ser., 364, 257-268, 2008.

Keith, D. W., Ha-Doung, M., and Stolaroff, J. K.: Climate strategy with $\mathrm{CO}_{2}$ capture from the air, Climatic Change, 74, 17-45, 
2006.

Kharecha, P. A. and Hansen, J. E.: Implications of "peak oil" for atmospheric $\mathrm{CO}_{2}$ and climate, Global Biogeochem. Cy., 22, GB3012, doi:10.1029/2007GB003142, 2008.

Kheshgi, H. S.: Sequestering Atmospheric carbon dioxide by increasing ocean alkalinity, Energy, 20, 915-922, 1995.

Kiehl, J. T. and Trenberth, K. E.: Earth's annual global mean energy budget, B. Am. Meterol. Soc., 78, 197-208, 1997.

Lacis, A., Alltop, J. L., Hsiang, S. M., Knobelspiesse, K. D., Li, J., and Pearl, C. B.: Some radiative aspects of proposed geoengineering countermeasures to global warming, Science, submitted, 2009.

Lacis, A. A. and Hansen, J. E.: A parameterization for the absorption of solar radiation in the Earth's atmosphere, J. Atmos. Sci., 31, 118-133, 1974.

Lackner, K. S., Wendt, C. H., Butt, D. P., Joyce, E. L., and Sharp, D. H.: Carbon dioxide disposal in carbonate minerals, Energy, 20, 1153-1170, 1995.

Lampitt, R. S., Achterberg, E. P., Anderson, T. R., Hughes, J. A., Iglesias-Rodriguez, M. D., Kelly-Gerreyn, B. A., Lucas, M., Popove, E. E., Sanders, R., Shepherd, J. G., SmytheWright, D., and Yool, A.: Ocean fertilization: a potential means of geoengineering, Philos. T. R. Soc. A, 366, 3919-3945 doi:10.1098/rsta.2008.0139, 2008.

Latham, J.: Control of global warming?, Nature, 347, 339-340, 1990.

Latham, J.: Amelioration of global warming by controlled enhancement of the albedo and longevity of low-level maritime clouds, Atmos. Sci. Lett., 3, 52-58, 2002.

Latham, J., Rasch, P., Chen, C.-C., Kettles, L., Gadian, A., Gettelman, A., Morrison, H., Bower, K., and Choularton, T.: Global temperature stabilization via controlled albedo enhancement of low-level maritime clouds, Philos. T. R. Soc. A, 366, 3969-3987, doi:10.1098/rsta.2008.0137, 2008.

Laws, E. A., Falkowski, P. G., Smith, W. O., Ducklow, H., and McCarthy, J. J.: Temperature effects on export production in the open ocean, Global Biogeochem. Cy., 14, 1231-1246, 2000.

Leake, J. E.: "Biosphere carbon stock management: Addressing the threat of abrupt climate change in the next few decades." By Peter Read, An editorial comment., Climatic Change, 87, 329-334, 2008.

Lehmann, J., Gaunt, J., and Rondon, M.: Bio-char sequestration in terrestrial ecosystems - a review, Mitigation and Adaptation Strategies for Global Change, 11, 403-427, 2006.

Lenton, T. M.: Land and ocean carbon cycle feedback effects on global warming in a simple Earth system model, Tellus, 52B, 1159-1188, doi:10.1034/j.1600-0889.2000.01104.x, 2000.

Lenton, T. M. and Watson, A. J.: Redfield revisited: 1. Regulation of nitrate, phosphate and oxygen in the ocean, Global Biogeochem. Cy., 14, 225-248, 2000.

Lenton, T. M.: Climate Change to the end of the Millennium, Climatic Change, 76, 7-29, doi:10.1007/s10584-005-9022-1, 2006.

Lenton, T. M. and Vaughan, N. E.: Interactive comment on "The radiative forcing potential of different climate geoengineering options" by T. M. Lenton and N. E. Vaughan, Atmos. Chem. Phys. Discuss., 9, S2658-S2672, 2009.

Li, Z. and Garand, L.: Estimation of surface albedo from space: A parameterization for global application, J. Geophys. Res.Atmos., 99, 8335-8350, 1994.
Loveland, T. R., Reed, B. C., Brown, J. F., Ohlen, D. O., Zhu, Z., Yang, L., and Merchant, J. W.: Development of a global land cover characteristics database and IGBP DISCover from $1 \mathrm{~km}$ AVHRR data, Int. J. Remote Sens., 21, 1303-1330, 2000.

Lovelock, J. E. and Rapley, C. G.: Ocean pipes could help the earth to cure itself, Nature, 449, p. 403, 2007.

MacCracken, M. C.: Geoengineering: Worthy of cautious evaluation?, Climatic Change, 77, 235-243, 2006.

Mackenzie, F. T., Ver, L. M., and Lerman, A.: Century-scale nitrogen and phosphorus controls of the carbon cycle, Chem. Geol., 190, 13-32, 2002.

Martin, J. H., Knauer, G. A., Karl, D. M., and Broenkow, W. W.: VERTEX: Carbon cycling in the northeast Pacific, Deep-Sea Res., 34, 267-285, 1987.

Najjar, R. G., Jin, X., Louanchi, F., Aumont, O., Caldeira, K., Doney, S. C., Dutay, J.-C., Follows, M., Gruber, N., Joos, F., Lindsay, K., Maier-Reimer, E., Matear, R. J., Matsumoto, K., Monfray, P., Mouchet, A., Orr, J. C., Plattner, G.-K., Sarmiento, J. L., Schlitzer, R., Slater, R. D., Weirig, M.-F., Yamanaka, Y., and Yool, A.: Impact of circulation on export production, dissolved organic matter, and dissolved oxygen in the ocean: Results from Phase II of the Ocean Carbon-cycle Model Intercomparison Project (OCMIP-2), Global Biogeochem. Cy., 21, GB3007, doi:10.1029/2006GB002857, 2007.

NAS: Policy Implications of Greenhouse Warming: Mitigation, Adaptation, and the Science Base, Washington, D.C., 1992.

Oman, L., Robock, A., Stenchikov, G. L., Schmidt, G. A., and Ruedy, R.: Climatic response to high-latitude volcanic eruptions, J. Geophys. Res.-Atmos., 110, D13103, doi:10.1029/2004JD005487, 2005.

Pacala, S. and Socolow, R.: Stabilization Wedges: Solving the Climate Problem for the Next 50 Years with Current Technologies, Science, 305, 968-972, 2004.

Pearson, J., Oldson, J., and Levin, E.: Earth rings for planetary environment control, Acta Astronaut., 58, 44-57, 2006.

Rasch, P. J., Crutzen, P. J., and Coleman, D. B.: Exploring the geoengineering of climate using stratospheric sulphate aerosols: The role of particle size, Geophys. Res. Lett., 35, L02809, doi:10.1029/2007GL032179, 2008.

Raupach, M. R., Marland, G., Ciais, P., LeQuere, C., Canadell, J. G., Klepper, G., and Field, C. B.: Global and regional drivers of accelerating $\mathrm{CO}_{2}$ emissions, P. Natl. Acad. Sci., 104, 1028810293, 2007.

Read, P. and Lermit, J.: Bio-energy with carbon storage (BECS): A sequential decision approach to the threat of abrupt climate change, Energy, 30, 2654-2671, 2005.

Read, P. and Parshotam, A.: Holistic greenhouse gas management strategy (with reviewers' comments and authors' rejoinders), Victoria University of Wellington, Wellington, New Zealand, http://ips.ac.nz/publications/publications/show/205, access: 9 July 2009, 2007.

Read, P.: Biosphere carbon stock management: addressing the threat of abrupt climate change in the next few decades: an editorial essay, Climatic Change, 87, 305-320, 2008.

Redfield, A. C.: The biological control of chemical factors in the environment, Am. Sci., 46, 205-221, 1958.

Ridgwell, A., Singarayer, J. S., Hetherington, A. M., and Valdes, P. J.: Tackling regional climate change by leaf albedo biogeoengineering, Curr. Biol., 19, 146-150, 2009. 
Roberts, G. C., Ramana, M. V., Corrigan, C., Kim, D., and Ramanathan, V.: Simultaneous observations of aerosol-cloudalbedo interactions with three stacked unmanned aerial vehicles, P. Natl. Acad. Sci., 105, 7370-7375, 2008.

Robock, A., Oman, L., and Stenchikov, G. L.: Regional climate responses to geoengineering with tropical and Arctic $\mathrm{SO}_{2}$ injections, J. Geophys. Res.-Atmos., 113, D16101, doi:10.1029/2008JD010050, 2008.

Rosenfeld, A. H., Romm, J. J., Akbari, H., and LLoyd, A. C.: Painting the town white and green, Technol. Rev., 100, 52-59, 1997.

Shepherd, J. G., Iglesias-Rodriguez, M. D., and Yool, A.: Geoengineering might cause, not cure, problems, Nature, 449, p. 781, 2007.

Smith, S. J., Pitcher, H., and Wigley, T. M. L.: Global and regional anthropogenic sulfur dioxide emissions, Global Planet. Change, 29, 99-119, 2001.

Stenchikov, G. L., Kirchner, I., Robock, A., Graf, H. F., Antuna, J. C., Grainger, R. G., Lambert, A., and Thomason, L.: Radiative forcing from the 1991 mount Pinatubo volcanic eruption, J. Geophys. Res.-Atmos., 103, 13837-13857, 1998.

Stern, D. I.: Global sulfur emissions from 1850 to 2000, Chemosphere, 58, 163-175, 2005.

Stern, N.: The Economics of Climate Change: The Stern Review, Cambridge University Press, Cambrige, 2006.

Taha, H.: Urban surface modification as a potential ozone airquality improvement strategy in California: a mesoscale modelling study, Bound.-Lay. Meteorol., 127, 219-239, 2008.

Teller, E., Wood, L., and Hyde, R.: Global Warming and Ice Ages: I. Prospects For Physics Based Modulation of Global Change, Lawrence Livermore National Laboratory (LLNL), CA (USA), Preprint UCRL-JC-128715, 1997.

Teller, E., Hyde, R., and Wood, L.: Active Climate Stabilization: Practical Physics-Based Approaches to Prevention of Climate Change, Lawrence Livermore National Laboratory (LLNL), CA (USA), Preprint UCRL-JC-148012, 2002.

Trenberth, K. E., Fasullo, J. T., and Kiehl, J. T.: Earth's global energy budget, B. Am. Meteorol. Soc., 90, 311-323, 2009.
Tsvetsinskaya, E. A., Schaaf, C. B., Gao, F., Strahler, A. H., Dickinson, R. E., Zeng, X., and Lucht, W.: Relating MODISderived surface albedo to soils and rock types over Northern Africa and the Arabian peninsula, Geophys. Res. Lett., 29, 1353, doi:10.1029/2001GL014096, 2002.

Twohy, C. H., Petters, M. D., Snider, J. R., Stevens, B., Tahnk, W., Wetzel, M., Russell, L., and Burnet, F.: Evaluation of the aerosol indirect effect in marine stratocumulus clouds: Droplet number, size, liquid water path, and radiative impact, J. Geophys. Res.Atmos., 110, D08203, doi:10.1029/2004JD005116, 2005.

Twomey, S.: Pollution and the planetary albedo, Atmos. Environ., 8, 1251-1256, 1974.

Twomey, S.: Aerosols, clouds and radiation, Atmos. Environ., 25A, 2435-2442, 1991.

Vaughan, N. E. and Lenton, T. M.: A review of climate geoengineering proposals, Climatic Change, submitted, 2009.

Vogt, M., Vallina, S., and von Glasow, R.: New directions: Correspondence on "enhancing the natural cycle to slow global warming”, Atmos. Environ., 42, 4803-4805, 2008.

Wigley, T. M. L.: A combined mitigation/geoengineering approach to climate stabilization, Science, 314, 452-454, 2006.

Wingenter, O. W., Elliot, S. M., and Blake, D. R.: New directions: Enhancing the natural sulphur cycle to slow global warming, Atmos. Environ., 41, 7373-7375, 2007.

Winjum, J. K., Dixon, R. K., and Schroeder, P. E.: Estimating the global potential of forest and agroforest management practices to sequester carbon, Water Air Soil Poll., 64, 213-227, 1992.

Woodhouse, M. T., Mann, G. W., Carslaw, K. S., and Boucher, O.: New Directions: The impact of oceanic iron fertilisation on cloud condensation nuclei, Atmos. Environ., 42, 5728-5730, 2008.

Zeebe, R. E. and Archer, D.: Feasibility of ocean fertilization and its impact on future atmospheric $\mathrm{CO}_{2}$ levels, Geophys. Res. Lett. 32, L09703, doi:10.1029/2005GL022449, 2005.

Zeman, F.: Energy and material balance of $\mathrm{CO}_{2}$ capture from ambient air, Environ. Sci. Technol., 41, 7558-7563, 2007.

Zhou, S. and Flynn, P. C.: Geoengineering downwelling ocean currents: A cost assessment, Climatic Change, 71, 203-220, 2005. 